\title{
Characterization of the Intracellular Localization, Processing, and Secretion of Two Glial Cell Line-Derived Neurotrophic Factor Splice Isoforms
}

\author{
Liina Lonka-Nevalaita, Maria Lume, Satu Leppänen, Eija Jokitalo, Johan Peränen, and Mart Saarma \\ Institute of Biotechnology, University of Helsinki, Viikki Biocenter, FIN-00014 University of Helsinki, Finland
}

\begin{abstract}
Endocrine and neuronal cells have highly developed secretion mechanisms, and the secretion can be either constitutive or regulated by physiological stimuli. In the constitutive pathway, intracellular transport vesicles undergo immediate fusion reactions after arrival at the target. In regulated secretion, vesicles accumulate near the target membrane until triggered to fuse, typically by a local rise in free $\mathrm{Ca}^{2+}$. In the present study, we characterize the processing and secretion mechanisms of the glial cell line-derived neurotrophic factor (GDNF). Although the function of GDNF has been extensively studied, very little is known about the basic cell biology of GDNF and its precursor forms $(\alpha)$ pro-GDNF and $(\beta)$ pro-GDNF that have different pro-regions. Our results show that both $(\alpha)$ pro-GDNF and $(\beta)$ pro-GDNF are secreted. We demonstrate that KCl-induced depolarization increases the secretion of $(\beta)$ pro-GDNF and corresponding mature GDNF, but not $(\alpha)$ pro-GDNF and corresponding mature GDNF, to the cell medium in a $\mathrm{Ca}^{2+}$-dependent manner. In parallel with this, immunofluorescence analysis of cells show that $(\alpha)$ pro-GDNF/GDNF is localized mostly in the Golgi complex, whereas $(\beta)$ pro-GDNF/GDNF is localized primarily in secretogranin II and Rab3A-positive vesicles of the regulated secretory pathway. In addition, we find that matrix metalloproteinases and plasmin that cleave pro-BDNF and pro-NGF are not responsible for the cleavage of pro-GDNF, whereas furin endoproteinase, PACE4, and proprotein convertases PC5A, PC5B, and PC7 can cleave pro-GDNF into mature GDNF. Thus, the processing and secretion mechanisms of GDNF are different from those of BDNF and NGF.
\end{abstract}

\section{Introduction}

Glial cell line-derived neurotrophic factor (GDNF) is a secretory protein that is widely expressed in the CNS and peripheral tissues. It is synthesized in the form of precursor pre-pro-GDNF that is proteolytically cleaved to mature, biologically active neurotrophic factor (Lin et al., 1993). In human and rodents, the GDNF gene encodes two mRNAs that are produced by alternative splicing: a full-length transcript [pre- $(\alpha)$ pro-GDNF] and a shorter transcript [pre- $(\beta)$ pro-GDNF] that lacks $78 \mathrm{bp}$ in the region encoding the pro-domain (Suter-Crazzolara and Unsicker, 1994; Trupp et al., 1995; Matsushita et al., 1997; Grimm et al., 1998). The function of GDNF has been studied extensively, but little is known about the basic cell biology, including processing and secretion of the two GDNF isoforms and their precursors.

GDNF is a distant member of the transforming growth factor- $\beta$ superfamily. Cellular responses to biologically active mature GDNF

Received Nov. 27, 2009; revised June 7, 2010; accepted July 1, 2010.

This work was supported by the Centre of Excellence program of the Academy of Finland, the Sigrid Jusélius Foundation, the National Technology Agency of Finland, and the Institute of Biotechnology, University of Helsinki. L.L.-N. was supported by the University of Helsinki postdoctoral fellowship and M.L. by European Union/Marie Curie Fellowship MEST-CT-2005-019729. We are grateful to Sharon Tooze for anti-Sgll antibody, Volkmar Lessmann for pre-pro-BDNF-EGFP, Nabil G. Seidah for cDNAs expressing PCs, PACE4, and furin, Kenneth Teng for CDNAs expressing wild-type and uncleavable NT3, Maria Lindahl for cDNA expressing GFRa1 receptor, Lauri Aaltonen for LoVo cell line, Urmas Arumäe and Eero Castrén for reviewing the manuscript, and Susanna Wiss and Mervi Lindman for excellent technical assistance.

Correspondence should be addressed to Mart Saarma, Institute of Biotechnology, University of Helsinki, Viikinkaari 9, FIN-00014 University of Helsinki, Finland. E-mail: mart.saarma@helsinki.fi.

DOI:10.1523/JNEUROSCI.5888-09.2010

Copyright $\odot 2010$ the authors $\quad 0270-6474 / 10 / 3011403-11 \$ 15.00 / 0$ homodimer are mediated by a multicomponent receptor consisting of glycosylphosphatidylinositol-linked ligand-binding GDNF family receptor $\alpha 1$ (GFR $\alpha 1$ ) and transmembrane Ret receptor tyrosine kinase (Durbec et al., 1996; Trupp et al., 1996). GDNF protects dopamine neurons in vitro and in animal models of Parkinson's disease (PD), which makes it a valuable candidate for therapeutic use in several neurodegenerative diseases, especially in PD (Lin et al., 1993; Björklund et al., 2000; Airaksinen and Saarma, 2002).

The secretion and function of the pro-forms of several other neurotrophic factors, especially nerve growth factor (NGF) and brain-derived neurotrophic factor (BDNF), have been well characterized. Mature NGF and BDNF induce neuronal survival, differentiation, and synaptic modulation (Huang and Reichardt, 2001), whereas uncleaved pro-BDNF and pro-NGF are proposed to induce cell death (Lee et al., 2001; Nykjaer et al., 2004). Moreover, BDNF and NGF, encoded by one splice isoform, are secreted via either constitutive or regulated pathway, depending on the cell type and stimulation (Thomas and Davies, 2005).

We have used primary cortical neurons as well as the PC-6.3 cell line, a subclone of the rat pheochromocytoma PC12 cell line, to study intracellular processing, cleavage, localization, and secretion of proteins encoded by pre- $(\alpha)$ pro-GDNF and pre$(\beta)$ pro-GDNF cDNAs. PC-6.3 cells are rat neuroendocrine cells, which exhibit a neuronal-like phenotype, primarily in response to NGF (Pittman et al., 1993). They have been studied extensively on mechanisms of vesicular sorting, because they provide both the constitutive and regulated secretory pathways (Tooze and Huttner, 1990; Lang et al., 1997). 
A

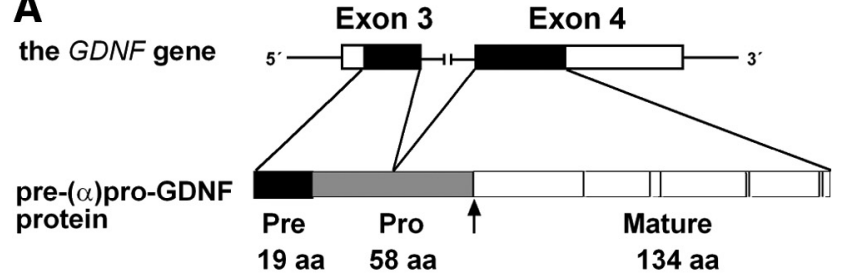

B B
the GDNF gene
$\begin{aligned} & \text { pre-( } \beta \text { )pro-GDNF } \\ & \text { protein }\end{aligned}$

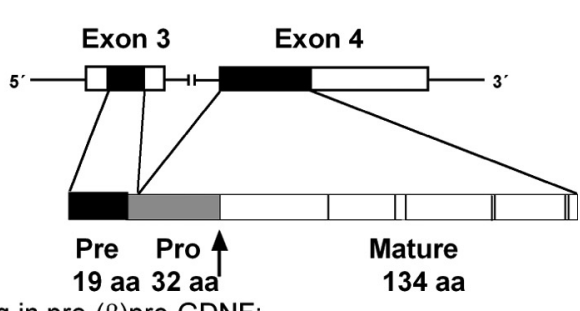

Aa sequence lacking in pre-( $(\beta)$ pro-GDNF

GKRPPEAPAEDRSLGRRRAPFALSSDS.

C

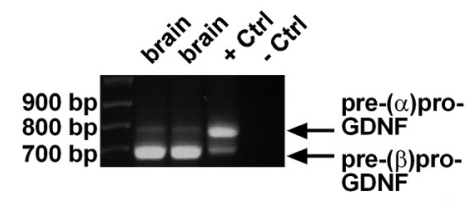

D

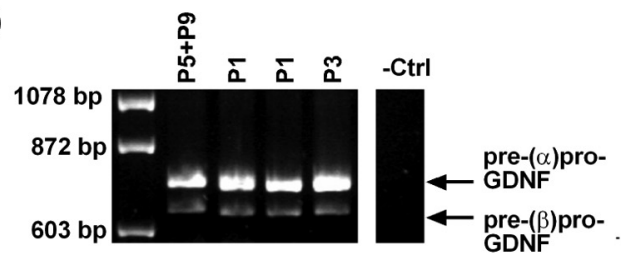

E

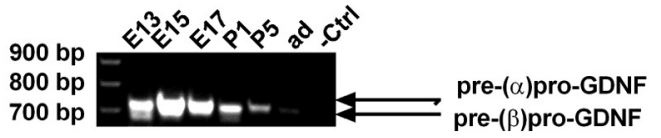

$\mathbf{F}$

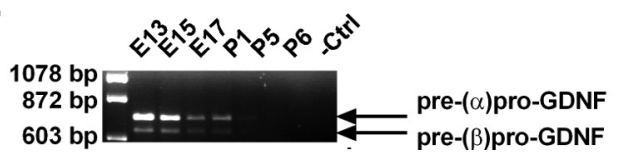

Figure 1. Characteristics of the GDNF splice variants and GDNF mRNA expression in the brain and kidney. $\boldsymbol{A}, \boldsymbol{B}$, Characteristics of pre- $(\alpha)$ pro-GDNF and pre- $(\beta)$ pro-GDNF splice variants. In the GDNF gene, exons 3 and 4 are shown as boxes, and the protein coding regions are shown in black. The introns, depicted as lines, are not drawn in scale. In the pre- $(\alpha)$ pro-GDNF and pre$(\beta)$ pro-GDNF proteins, the number of amino acids in mature molecules in white, pro-regions in gray, and pre-regions in black are shown. For clarity, N-terminal signal sequences (pre-regions) are included, although they are cleaved during the protein translation. Relative positions of the seven conserved cysteine residues in the mature GDNF are shown as black bars, and the putative cleavage sites of pro-domains are indicated with arrows. Alternative splicing of the GDNF gene leads to 26 aa deletion and 1 aa substitution (the N-terminal $G$ to $A$ ) in the pro-region of the pre- $(\beta)$ pro-GDNF protein compared with the pre- $(\alpha)$ pro-GDNF protein. $\mathbf{C}-\boldsymbol{F}, \mathrm{RT}-\mathrm{PCR}$ analysis of the GDNF mRNA expression in human adult brain $(\boldsymbol{C})$, in mouse hippocampal neuronal cultures from $\mathrm{P} 1-\mathrm{P} 9$ animals, cultured 3 or $4 \mathrm{~d}$ in vitro (D), in developing mouse brain $(\boldsymbol{E})$, and in mouse kidney at different developmental stages $(\boldsymbol{F})$. The PCR products of pre- $(\alpha)$ pro-GDNF and pre- $(\beta)$ pro-GDNF variants are marked with arrows. $\mathrm{H}_{2} \mathrm{O}$ or human $\mathrm{CDNA}$ were used as templates in negative $(-C$ trl) and positive $(+C$ trl) control reactions.

Here we report that the processing and secretion mechanisms of GDNF are different from those of BDNF and NGF. We show that $\mathrm{KCl}$-induced depolarization increases the secretion of $(\beta)$ pro-GDNF and corresponding mature GDNF but not $(\alpha)$ pro-GDNF and corresponding mature GDNF, to the cell medium in a calcium-dependent manner. Moreover, $(\alpha)$ proGDNF/GDNF is localized mostly in the Golgi, whereas $(\beta)$ pro-
GDNF/GDNF is localized primarily in secretogranin II (SgII) and Rab3A-positive vesicles of the regulated secretory pathway. Differently from pro-BDNF and pro-NGF, we show that matrix metalloproteinase (MMPs) and plasmin are not responsible for the cleavage of pro-GDNF to yield mature GDNF. Similarly to pro-BDNF and pro-NGF, we show that $(\alpha)$ pro-GDNF and $(\beta)$ pro-GDNF can be secreted as pro-GDNF proteins.

\section{Materials and Methods}

Reverse transcription-PCR, generation of expression constructs, and primers. The expression of pre- $(\alpha)$ pro-GDNF and pre- $(\beta)$ pro-GDNF cDNAs was analyzed by reverse transcription (RT)-PCR. Total RNAs from mouse brain, kidney, and primary neuronal cultures were isolated using the TRIzol Reagent (Invitrogen). Human RNAs were obtained from Clontech. RT reactions were prepared from $5 \mu \mathrm{g}$ of RNA using the reverse transcriptase (Superscript ${ }^{\mathrm{II}}$; Invitrogen) kit and oligo-dT (Promega) primers.

For expression analysis, mouse pre- $(\alpha)$ pro-GDNF and pre- $(\beta)$ proGDNF cDNAs were cloned from testis and kidney by RT-PCR and cloned into the pCR2.1 vector. The cDNAs were cleaved from pCR2.1 vector and ligated into phosphorylated enhanced green fluorescent protein (pEGFP)-N1 vector (Invitrogen) using restriction sites of HindIII and XhoI. For production of GDNF pro-glutathione $S$-transferase fusion proteins, the cDNAs encoding the pro-regions of mouse pre- $(\alpha)$ proGDNF and pre- $(\beta)$ pro-GDNF were cloned into pGEX-4T- 1 vector using BamHI and XhoI restriction sites.

Human pre- $(\alpha)$ pro-GDNF and pre- $(\beta)$ pro-GDNF cDNAs were cloned from human kidney and brain RNA (Clontech) by RT-PCR and cloned first into the pCR2.1 vector and next into pEGFP-N1 vector as described above. In addition, human pre- $(\alpha)$ pro-GDNF and pre$(\beta)$ pro-GDNF cDNAs were cloned into pAAV-multiple cloning site (MCS) and pAAV-internal ribosomal entry site (IRES)-humanized Renilla GFP (hrGFP) expression vectors (Stratagene) using restriction sites BamHI and Xhol. To produce uncleavable pro-GDNFs, pAAVMCS constructs expressing human pre- $(\alpha)$ pro-GDNF and pre- $(\beta)$ proGDNF carrying either (1) Lys to Ala substitutions in residues $(-5)$ and $(-2)$ and Arg to Ala mutations in residues $(-4)$ and $(-1)$ or (2) Lys to Ala substitutions in residues $(-5)$ and $(-2)$ and Arg to Ala mutations in residues $(-4),(-1), 11$ and 12 were cloned using the Phusion sitedirected mutagenesis kit (Finnzymes). All clonings were verified by sequencing. A pEGFP-N1 construct expressing rat pre-pro-BDNF-EGFP was a gift from Volkmar Lessmann (Otto von Guericke University, Magdeburg, Germany). Constructs expressing wild-type (WT) neurotrophin 3 (NT3) and uncleavable NT3 were gifts from Kenneth Teng (Weill Cornell Medical College, New York, NY). Constructs expressing proprotein convertases (PCs), furin, and paired basic amino acid cleaving enzyme 4 (PACE4) were gifts from Nabil G. Seidah (Institut de Recherches Cliniques de Montréal, Montréal, QC, Canada). A construct expressing GFR $\alpha 1$ was a gift from Maria Lindahl (University of Helsinki, Helsinki, Finland). A construct expressing vesicular stomatitis virus glycoprotein $G$ protein has been described previously (Keller et al., 2001). Constructs pEGFP-Rab3A and pEGFP-Rab27A were generated by cloning the open reading frame of these genes from human CDNA into PEGFP-C1A, and pEGFP-Rab3A-T36N was created by site-directed mutagenesis using inverse PCR.

Primers used for cloning of mouse pre- $(\alpha)$ pro-GDNF and pre- $(\beta)$ proGDNF into pCR2.1 were first forward (5'-GCTCCTGCCCGAGGTC- $\left.3^{\prime}\right)$, first reverse (5'-CCTTTCTTCGCACTGTAGCAG- $\left.3^{\prime}\right)$, nested forward $\left(5^{\prime}\right.$ GTCCGGATGGGTCTCCTGG-3'), and nested reverse (5'-CACAGCAGTCTCTGGAGCCG-3'). Primers used for cloning of mouse pre$(\alpha)$ pro-GDNF and pre- $(\beta)$ pro-GDNF into pEGFP-N1 were forward $\left(5^{\prime}\right.$ CAACTCGAGCAAATGGGATTCGGGCCACTTGGA- $3^{\prime}$ ) containing Xhol site and reverse (5'-CCAAAGCTTCCATCAGATACATCCACACCGTTTAG- ${ }^{\prime}$ ) containing HindIII site. Primers used for cloning of the pro-region of mouse pre- $(\alpha)$ pro-GDNF in pGEX-4T- 1 were forward $\left(5^{\prime}\right.$ CAATGGATCCTTCCCGCTGCCCGCCGGTAA- $3^{\prime}$ ) containing BamHI site and reverse (5'-ATTGCTCGAGTCACCTTTTCAGTCTTTTAATGGTGGC- $3^{\prime}$ ) containing XhoI site and for cloning of the pro-region of mouse pre- $(\alpha)$ pro-GDNF forward (5' -CAATGGATCCTTCCCGCT- 

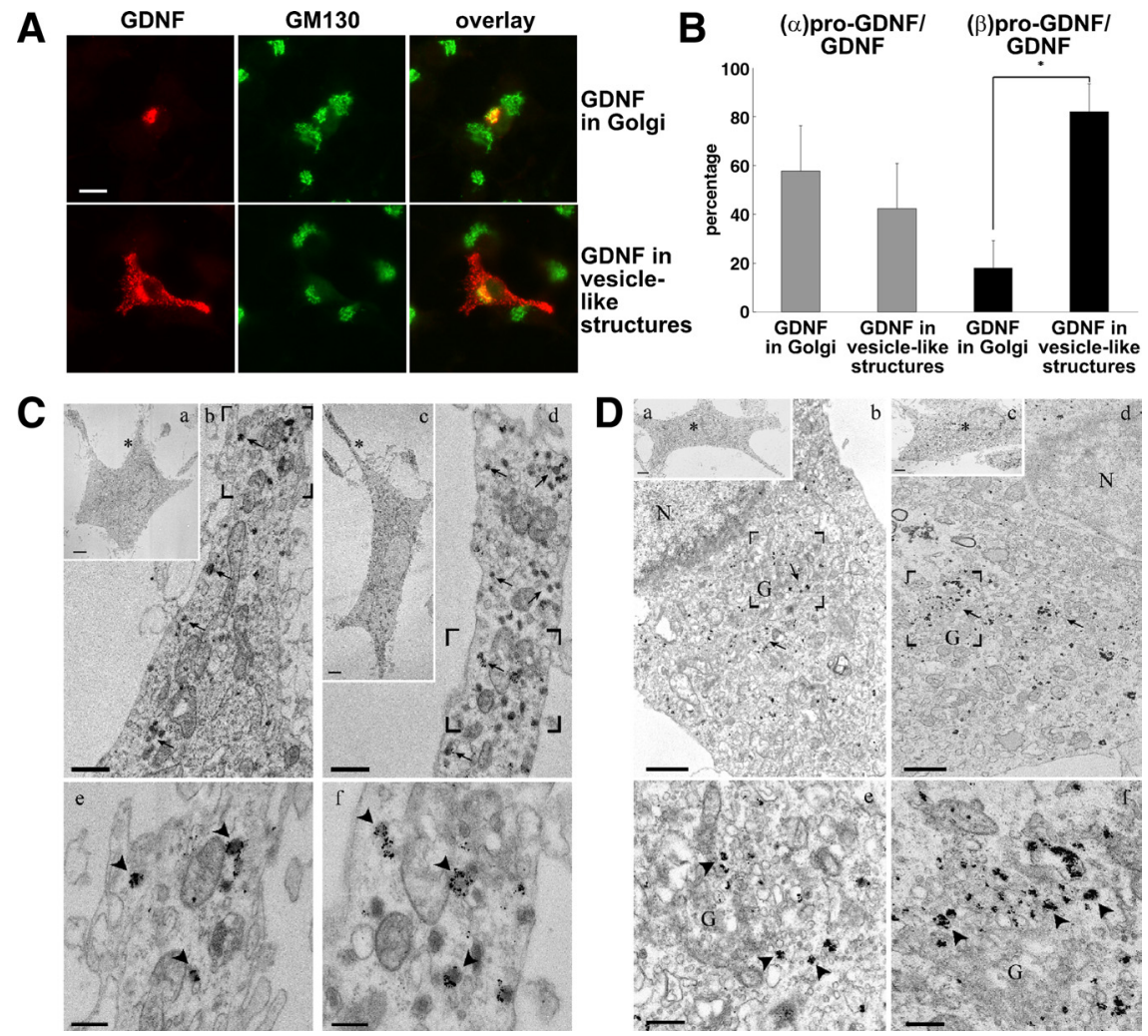

Figure 2. Proteins encoded by pre- $(\alpha)$ pro-GDNF and pre- $(\beta)$ pro-GDNF cDNA localize to Golgi and DCVs in NGF-differentiated PC-6.3 cells. $\boldsymbol{A}-\boldsymbol{D}$, Localization of proteins encoded by human pre- $(\alpha)$ pro-GDNF or pre- $(\beta)$ pro-GDNF CDNA in NGF-differentiated PC-6.3 cells $(\boldsymbol{A})$. Double immunofluorescence stainings with anti-GDNF antibody (red) and anti-GM130 antibody for cis-to medialGolgi marker protein (green). The GDNF-specific staining patterns detected are Golgi staining and vesicle-like staining. PlanApo $40 \times / 1.00$ (oil) objective (Olympus) was used. Scale bar, $10 \mu \mathrm{m}$. B, Quantification of localizations of the proteins encoded by pre- $(\alpha)$ pro-GDNF (gray bars) or pre- $(\beta)$ pro-GDNF (black bars) in Golgi and in vesicle-like structures $(n=3) .{ }^{*} p=0.0023$. Error bars show SD. $\boldsymbol{C}$, IEM analysis of cells transfected with pre- $(\alpha)$ pro-GDNF $(\boldsymbol{a}, \boldsymbol{b}, \boldsymbol{e})$ or pre- $(\beta) \operatorname{pro-GDNF}(\boldsymbol{c}, \boldsymbol{d}, \boldsymbol{f})$ CDNAs. In neurites, DCVs (arrows) are gathered nearby the plasma membrane $(\boldsymbol{b}, \boldsymbol{d})$. The anti-GDNF antibody-specific staining in DCVs (arrowheads) is shown in higher magnification $(\boldsymbol{e}, \boldsymbol{f})$. Small insets $(\boldsymbol{a}, \boldsymbol{c})$ show overview of the whole cell, in which magnified extension is marked (asterisk). Scale bars: $\boldsymbol{a}, \boldsymbol{c}, 5 \mu \mathrm{m} ; \boldsymbol{b}, \boldsymbol{d}, 0.5 \mu \mathrm{m} ; \boldsymbol{e}, \boldsymbol{f}, 0.25 \mu \mathrm{m}$. $\boldsymbol{D}$, IEM analysis of cells transfected with pre-( $\alpha) \operatorname{pro}-\operatorname{GDNF}(\boldsymbol{a}, \boldsymbol{b}, \boldsymbol{e})$ or pre- $(\beta)$ pro-GDNF $(\boldsymbol{c}, \boldsymbol{d}, \boldsymbol{f})$ CDNAs. Black clustered dots (arrows) indicate the localization of GDNF in Golgi complex $(\boldsymbol{c}, \boldsymbol{d})$. The anti-GDNF antibody-specific staining in Golgi complex transport vesicles is shown in higher magnification. Protein overexpression causes tubularization of the Golgi complex. Small insets $(\boldsymbol{a}, \boldsymbol{c})$ show overview of the whole cell, in which Golgi area is highlighted (asterisk). Nucleus (N) and Golgi complex (G) are indicated. Scale bars: $\boldsymbol{a}, \boldsymbol{c}, 5 \mu \mathrm{m} ; \boldsymbol{b}, \boldsymbol{d}, 0.5 \mu \mathrm{m} ; \boldsymbol{e}, \boldsymbol{f}, 0.25 \mu \mathrm{m}$.

GCCCGCCGCCAA-3') containing BamHI site and reverse (5'-ATTGCTCGAGTCACCTTTTCAGTCTTTTAATGGTGGC-3') containing XhoI site. Primers used for cloning of human pre- $(\alpha)$ pro-GDNF and pre- $(\beta)$ pro-GDNF into pCR2.1 were first forward $\left(5^{\prime}\right.$-GACCTGTTGGGCGGGGCTC-3'), first reverse ( $5^{\prime}$-CCTGGGAACCTTGGTCCCTTTC-3'), nested forward ( $5^{\prime}$-GCTCCAGCCATCAGCCCGG-3'), and nested reverse ( $5^{\prime}$-CACAGCAGTCTCTGGAGCCGG-3'). For expression analysis, the cDNAs were cleaved from pCR2.1 and cloned into pEGFP-N1 using restriction enzymes XhoI and HindIII. Primers used for cloning of human pre- $(\alpha)$ pro-GDNF and pre- $(\beta)$ pro-GDNF into pAAVMCS and pAAV-IRES-hrGFP were forward ( $5^{\prime}$-CAACAAGGATCCATGAAGTTATGGGATGTCGTGG-3') containing BamHI site and reverse (5'-CCACCACTCGAGTCAGATACATCCACACCTTTTAG-3') containing XhoI site. Primers used for cloning of $4 \mathrm{~A}$ mutation into human pre$(\alpha)$ pro-GDNF and pre- $(\beta)$ pro-GDNF were forward ( $5^{\prime}$-CTGGCAGCGTCACCAGATAAACAAATGGCAGTGC-3') and reverse (5'CGCTGCAATGGTGGCTTGAatAaAatCCATGACATC- $3^{\prime}$ ). Primers used for cloning of $6 \mathrm{~A}$ mutation into human pre- $(\alpha)$ pro-GDNF(4A) and pre- $(\beta)$ pro-GDNF(4A) were forward (5'-AGAGCGGAATCGGCAGGCTGCAG-3') and reverse (5'- GCTGCAGGAAGCACTGCCATTTGTTTATC- $3^{\prime}$ ).

Antibodies. A polyclonal peptide antibody anti-pro-GDNF against the GDNF pro-region was produced by immunizing rabbits with a synthetic

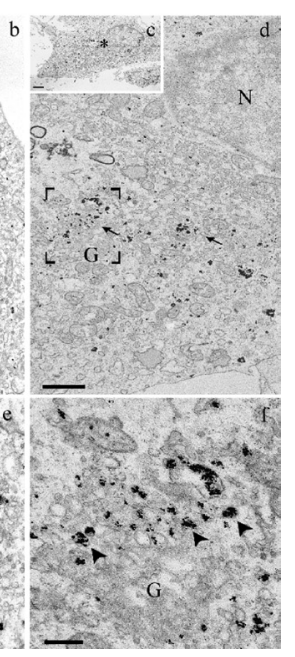

polypeptide 321 (CPEDYPDQFDDVMD) corresponding to amino acids -24 to -12 of the human and mouse $(\alpha)$ pro-GDNF and $(\beta)$ proGDNF sequences (Inbiolabs). One cysteine residue was added to the $\mathrm{N}$ terminus of the peptide. The pure 321 peptide was conjugated to carrier protein keyhole limpet hemocyanin, to stimulate an immune response in the subsequent immunization process. Purification of the antibody from the blood antiserum was done using IgGpurification MAbsorbent technology. Polyclonal anti-SgII(175) antibody was a gift from Sharon A. Tooze (Cancer Research UK, London Research Institute, London, UK) (Dittie and Tooze, 1995). Monoclonal anti-GDNF antibody G90 was a gift from Amgen. The following primary antibodies were obtained from commercial sources: a polyclonal anti-GDNF D20 (Santa Cruz Biotechnology), a polyclonal anti-GDNF (Genway Biotech), a monoclonal anti-GM130 (BD Biosciences), a monoclonal anti-MAP2 (Millipore Bioscience Research Reagents), a monoclonal anti-FLAG M2 (Sigma), and a monoclonal anti-GFR $\alpha 1$ (R \& D Systems). For immunofluorescence (IF), cyanine 2 (Cy2)-conjugated donkey anti-mouse IgG (Jackson ImmunoResearch), Cy3-conjugated donkey anti-rabbit IgG (Jackson ImmunoResearch), Cy5-conjugated donkey anti-mouse IgG (Jackson ImmunoResearch), Alexa Fluor 568-conjugated goat anti-rabbit IgG (Invitrogen), and Alexa Fluor 568-conjugated goat antimouse IgG (Invitrogen) were used as secondary antibodies. The nuclei were labeled with Hoechst 33342 (1:1000; Invitrogen). For Western blot (WB), HRP-conjugated donkey anti-rabbit Ig secondary antibody (Dako) and HRP-conjugated goat anti-mouse secondary antibody (Dako) were used as a secondary antibody.

Cell culture, transient transfections, and stimulations. $\mathrm{CHO}$ and PC-6.3 cell lines were grown in differentiation medium (DME) containing antibiotics together with either 10\% FBS $(\mathrm{CHO})$ or $10 \%$ horse serum and $5 \%$ FBS (PC-6.3). LoVo cells were grown in DME containing $1.5 \mathrm{~g} / \mathrm{L} \mathrm{NaHCO}_{3}, 2 \mathrm{~mm}$ glutamine, and $10 \%$ FBS. Cells were transfected using Lipofectamine 2000 (Invitrogen) transfection protocol. For NGF differentiation, undifferentiated PC-6.3 cells were seeded on collagen (Sigma)-coated plates and grown in differentiation medium (DME, $5 \%$ horse serum and 2.5\% FCS, $50 \mathrm{ng} / \mathrm{ml} \mathrm{NGF}$, and antibiotics) for 3-4 d. For stimulations, the differentiation medium of transfected PC-6.3 cells was replaced with DME or DME containing KCl. For Western blot analysis, the transfected cells were incubated with $25 \mathrm{~mm} \mathrm{KCl}$ for $5 \mathrm{~h}$ followed by collection and concentration of the media and detection of GDNF using antiGDNF (D20) antibody. For GDNF and BDNF ELISA, the transfected cells were incubated with DME, DME containing $50 \mathrm{~mm} \mathrm{KCl}$, or DME containing $50 \mathrm{~mm} \mathrm{KCl}$ together with $20 \mu \mathrm{m}$ calcium chelator BAPTA-AM (Fluka) for $2 \mathrm{~h}$ followed by collection of the media and analysis. BAPTA-AM, which was added 20 min before treatment with $\mathrm{KCl}$, was used for inhibition of stimulation. For immunofluorescence analysis, the transfected cells were incubated with $50 \mathrm{~mm} \mathrm{KCl}$ for $2 \mathrm{~h}$, and GDNF was detected using polyclonal or monoclonal anti-GDNF antibody or anti-pro-GDNF antibody. The protein synthesis was stopped with $50 \mu \mathrm{g} / \mathrm{ml}$ cycloheximide (Sigma).

Hippocampal and cortical neuron preparations and transfections. Hippocampi and cortices were dissected from embryonic day 18 (E18) rats. Tissues were digested with $0.25 \%$ trypsin in HBSS for 10-15 min (hippocampi) or $30 \mathrm{~min}$ (cortices) at $37^{\circ} \mathrm{C}$. DNase I $(1 \mathrm{mg} / \mathrm{ml})$ was added, and sample was triturated with siliconized glass pipette. Cells were washed three times with HBSS containing $10 \mathrm{~mm}$ glucose (Sigma) and plated on poly-D- 
lysine hydrobromide (Sigma)-coated coverslips in four-well plates. The cultures were grown in Neurobasal medium (Invitrogen) supplemented with L-glutamate (Invitrogen), 1× B-27 (Invitrogen), and antibiotics (primocin). For transfections, the cells were incubated for $2 \mathrm{~h}$ with Neurobasal medium containing $10 \mathrm{~mm} \mathrm{MgCl}_{2}$ followed by transfection using Lipofectamine 2000 transfection protocol.

Immunocytochemistry. PC-6.3 cells were differentiated for $3 \mathrm{~d}$, and primary neurons were grown in vitro for 16 or $17 \mathrm{~d}$ before transfection. Cells were fixed in $4 \%$ paraformaldehyde $24 \mathrm{~h}$ after transfection, blocked with $0.5 \%$ BSA (Sigma), and permeabilized with $0.1 \%$ Triton X-100 (Sigma). Cells were incubated with primary antibodies in $0.5 \%$ BSA in room temperature for $1 \mathrm{~h}$, washed, and then repeated with secondary antibodies. In surface labeling, the nonpermeabilized living cells were incubated with primary antibodies on ice for $30 \mathrm{~min}$, followed by fixation and staining with secondary antibodies. GDNF was detected with polyclonal anti-GDNF (GenWay Biotech), monoclonal antiGDNF (G90), or anti-pro-GDNF antibody. Nuclei were stained with Hoechst 33342 (Invitrogen), and coverslips were mounted with Immumount (Thermo Fisher Scientific).

For the wide-field fluorescence image acquirement, the AnalySIS software (Olympus) and PlanApo $60 \times / 1.40$ (oil) objective (Olympus) or UPlanApo $40 \times / 1.00$ (oil) objective (Olympus) was used. The confocal microscope lasers used were diode-pumped solid-state $561 \mathrm{~nm} / 20 \mathrm{~mW}$ and optically pumped semiconductor laser 488 $\mathrm{nm} / 270 \mathrm{~mW}$; the objective used was a HCX APO $63 \times / 1.30$ (glycerol) corr CS 21 . The confocal image stacks were deconvoluted with AutoQuant X AutoDeblur 3D Blind Deconvolution (Media Cybernetics), and the three-dimensional reconstructions were made with Imaris 6.2.1 (Bitplane). The Pearson's coefficient in colocalized volume was calculated using Imaris 6.2.1 Coloc tool (Costes et al., 2004). The value of one indicates complete positive correlation and zero indicates no correlation. The statistical significance was assessed by Student's $t$ test.

Immunoelectron microscopy. PC-6.3 cells were NGF differentiated for $3 \mathrm{~d}$ before transfections. To be able to identify transfected cells by GFP signal, cells were transfected with human pre- $(\alpha)$ pro-GDNF and pre- $(\beta)$ pro-GDNF in pAAV-IRES-hrGFP encoding GFP separately. After $24 \mathrm{~h}$ transfection, the cells growing on collagencoated plastic coverslips (Millipore Bioscience Research Reagents) were fixed with PLP fixative ( $2 \%$ formaldehyde, $0.01 \mathrm{M} \mathrm{NaIO}_{4}$, and $0.075 \mathrm{M}$ lysine$\mathrm{HCl}$ in $0.037 \mathrm{M}$ phosphate buffer, $\mathrm{pH} 7.4$ ) for $2 \mathrm{~h}$ at room temperature. Cells were permeabilized with $0.01 \%$ saponin (Sigma) and immunolabeled using monoclonal anti-GDNF (G90) as a first antibody and $1.4 \mathrm{~nm}$ gold particleconjugated Fab' fragments against mouse IgG (Nanoprobes) as a second antibody. Nano gold particles were silver enhanced for 1-5 min (using HQ Silver Enhancement kit; Nanoprobes) and gold toned with $0.05 \%$ gold chloride (Arai et al., 1992). After washing, the cells were dehydrated in an alcohol series and processed for Epon embedding while still on coverslips (Seemann et al., 2000). Sections were cut parallel to coverslip, poststained with uranyl acetate and lead citrate, and detected using a JEOL JEM-1200EX II transmission electron microscope operating at $60 \mathrm{kV}$. Images were acquired with ES500W CCD camera (Gatan).

Western blot. Transfected cells were grown in serum-free growth medium (CHO, PC-6.3, and LoVo). Cells and media were collected 48 or $72 \mathrm{~h}$ after
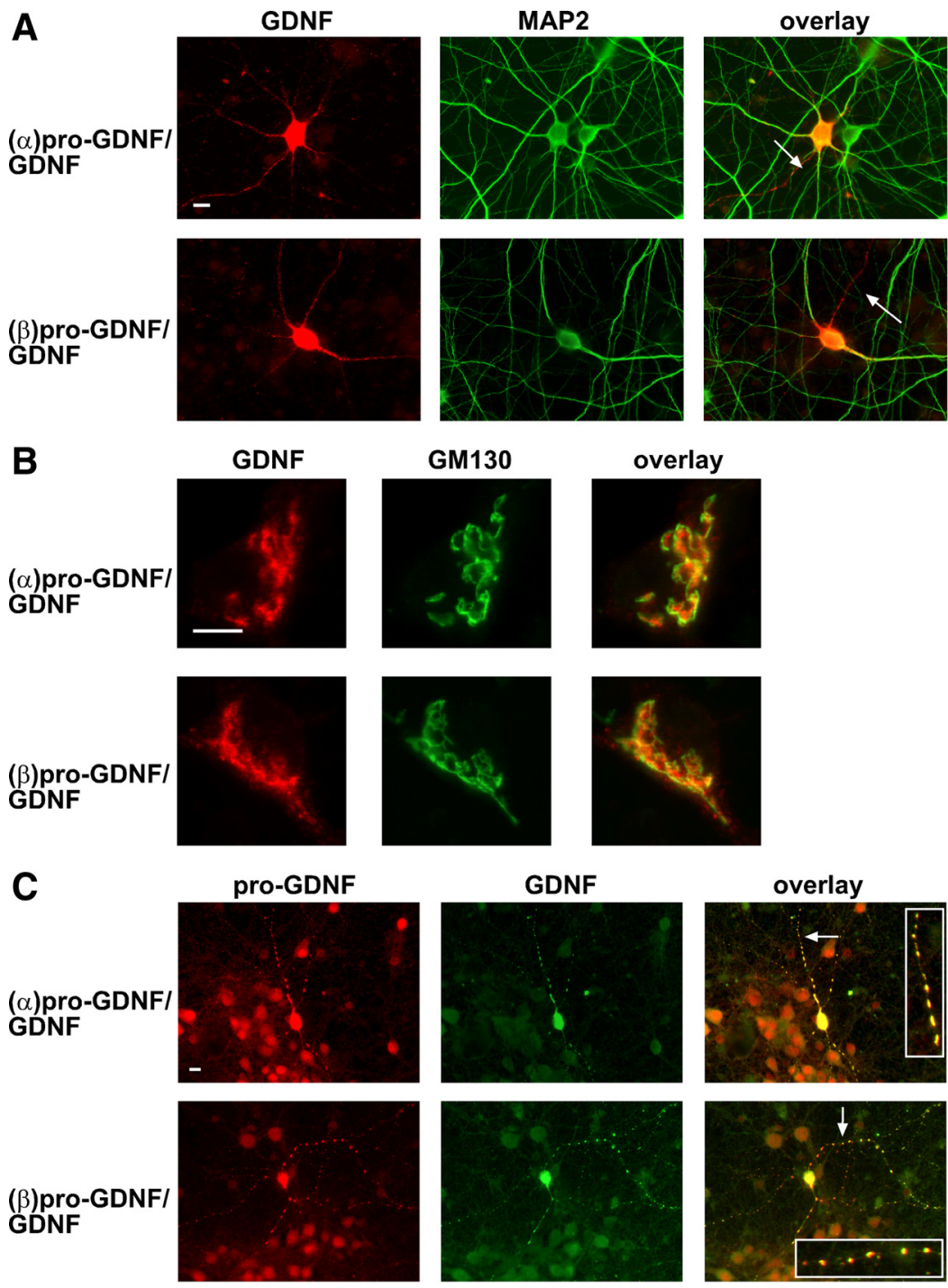

Figure 3. Proteins encoded by pre- $(\alpha)$ pro-GDNF and pre- $(\beta)$ pro-GDNF cDNA localize to both dendrites and axons in rat primary GDNF or pre- $(\beta)$ pro-GDNF cDNA. $A$, Stainings for GDNF (red) and dendritic marker protein MAP2 (green) in E18 rat cortical primary neurons (16 d in vitro). MAP2-negative and GDNF-positive axons are indicated with arrows. Scale bar, $10 \mu \mathrm{m}$. $\boldsymbol{B}$, Stainings for GDNF , Stainings for pro-GDNF (red) and mature GDNF (green) in E18 rat cortical primary neurons (17 d in vitro). PlanApo 40×/1.00 (oil) objective (Olympus) was used. Insets are magnifications of the regions indicated by arrows. Scale bar, $10 \mu \mathrm{m}$.

transfection and separated by SDS-PAGE, followed by blotting into nylon membrane. GDNF was detected with anti-GDNF (D20) or anti-pro-GDNF antibody. All medium samples, except WT and mutant GDNF samples shown in Figures $6 C$ and $7 E$ and mutant GDNF samples shown in Figure $6 E$, were concentrated using Amicon Ultra-4 Centrifugal Filter Units (Millipore Corporation).

Endoglycosidase digestion. Growth media (Opti-MEM) of transfected $\mathrm{CHO}$ cells were collected $48 \mathrm{~h}$ after transfection, denatured, and incubated with $1 \mu \mathrm{l}$ of PNGase F (15,000 U/ml; New England Biolabs) for $1 \mathrm{~h}$ at $37^{\circ} \mathrm{C}$. The media from wild-type pre- $(\alpha)$ pro-GDNF and pre- $(\beta)$ pro-GDNF transfected cells were concentrated before PNGase F treatment. Samples were analyzed by WB.

Processing by proprotein convertases. Proprotein convertase cDNA constructs, including mouse $(\mathrm{m}) \mathrm{PC} 1, \mathrm{mPC} 2, \mathrm{mPC} 5 \mathrm{~A}, \mathrm{mPC} 5 \mathrm{~B}$, human full-length furin, soluble furin, PACE4, and rat PC7 were transiently cotransfected to LoVo cells with human pre- $(\alpha)$ proGDNF. GDNF cotransfected with GFP was used as a control. At $48 \mathrm{~h}$ after transfection, media were collected and samples were analyzed by WB. 

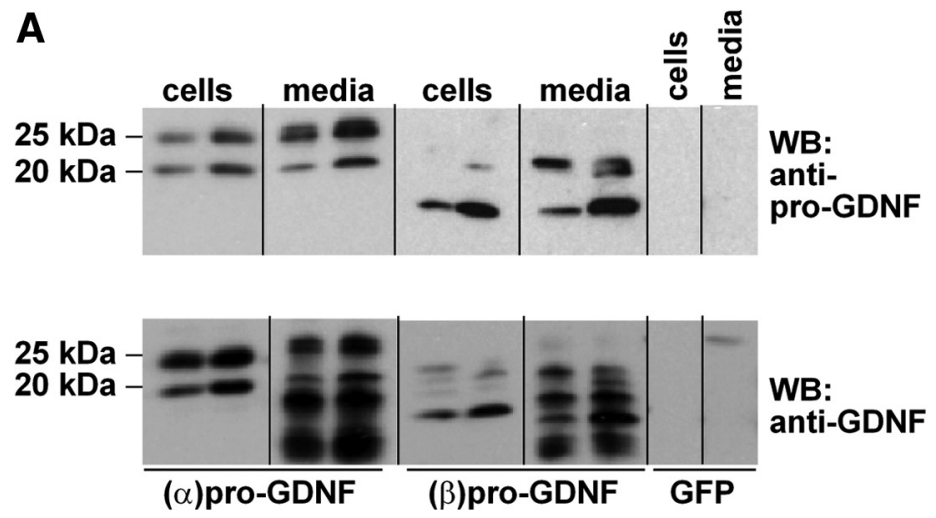

B
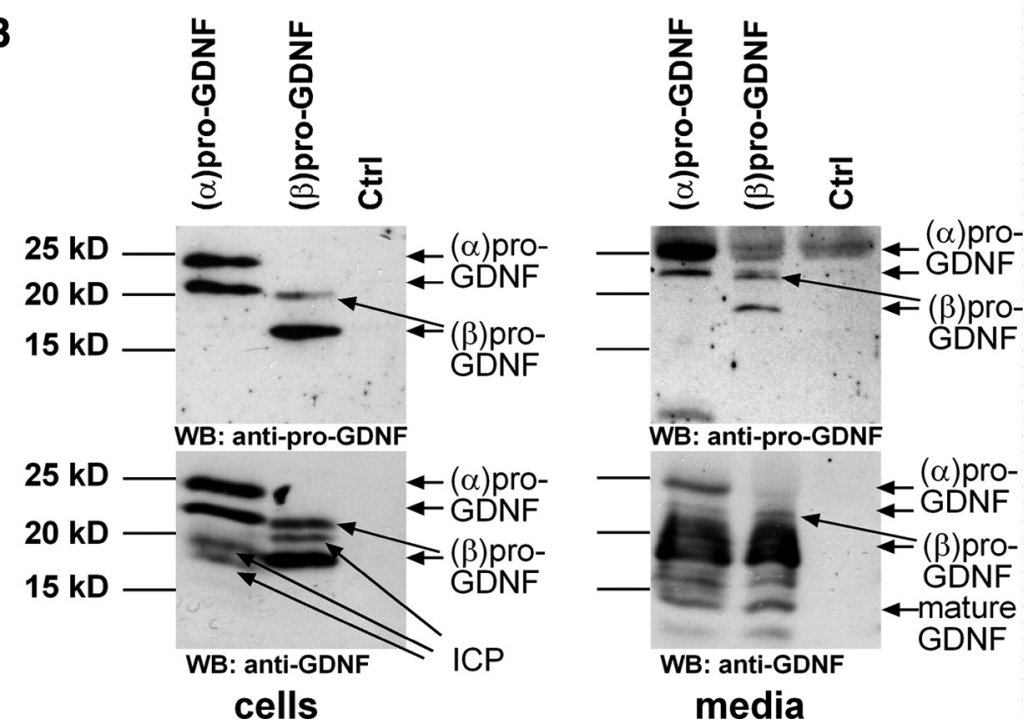

Figure 4. $\quad(\alpha)$ pro-GDNF and $(\beta)$ pro-GDNF are secreted in mature GDNF, and pro-GDNF forms from cell lines. Human pre- $(\alpha)$ pro GDNF and pre- $(\beta)$ pro-GDNF CDNAs were expressed in $\mathrm{CH} 0$ cells $(\boldsymbol{A})$ and PC-6.3 cells $(\boldsymbol{B})$. Cells and media were collected, concentrated, and analyzed by Western blotting using anti-pro-GDNF and anti-GDNF antibodies. $A$, In each GDNF sample, the lane on the left represents GDNF expressed from pAAV-MCS vector, and the lane on the right represents GDNF expressed from pAAV-IRES- hrGFP vector. Expression of GFP was used as control. B, GDNF was expressed from pAAV-MCS vector. Nontransfected cells were used as controls (Ctrl). The bands representing $(\alpha)$ pro-GDNF, $(\beta)$ pro-GDNF, mature GDNF, or intermediate cleavage products (ICP) are marked with arrows.

Inhibition of proteolytic cleavage. After transfection of cells, furin endoproteinase inhibitor (30 $\mu \mathrm{M}$; Calbiochem), broad-spectrum MMP inhibitor (GM6001; $10 \mu \mathrm{M}$; Calbiochem), or $\alpha 2$ anti-plasmin $(1 \mu \mathrm{g} / \mathrm{ml}$; Calbiochem) were added to the growth media (Opti-MEM). After $48 \mathrm{~h}$, media were collected, concentrated, and analyzed by WB.

ELISA. ELISAs, which do not discriminate mature GDNF or BDNF from the pro-GDNF or pro-BDNF forms, were performed using GDNF Emax Immunoassay System (Promega) and BDNF Emax Immunoassay system (Promega), according to the recommendations of the supplier. Protease inhibitor PMSF (1:100) was added to the samples before analysis. All experiments were performed in the set of three or four repeats. The statistical significance was assessed by Student's $t$ test.

\section{Results}

Pre- $(\boldsymbol{\alpha})$ pro-GDNF and pre- $(\boldsymbol{\beta})$ pro-GDNF mRNAs are expressed in the brain and kidney development The GDNF gene encodes two GDNF mRNA variants called here pre- $(\alpha)$ pro-GDNF and pre- $(\beta)$ pro-GDNF (Suter-Crazzolara and Unsicker, 1994; Trupp et al., 1995) (Fig. 1A,B). These variants are produced by alternative splicing of the GDNF mRNA. Compared with pre- $(\alpha)$ pro-GDNF mRNA, pre- $(\beta)$ pro-GDNF mRNA lacks 78 bp in the $3^{\prime}$ end of the exon 3 leading to the loss of 26 aa and substitution of 1 aa in the pro-region of $(\beta)$ proGDNF protein (Grimm et al., 1998) (Fig. $1 A, B$ ). Human and murine pre- $(\alpha)$ pro-GDNF and pre$(\beta)$ pro-GDNF splice variant mRNAs are expressed in the CNS as well as in many non-neuronal tissues (Suter-Crazzolara and Unsicker, 1994; Matsushita et al., 1997; Grimm et al., 1998). We confirmed the presence of pre- $(\alpha)$ pro-GDNF and pre- $(\beta)$ pro-GDNF mRNAs in human adult brain (Fig. $1 C$ ), mouse brain (Fig. $1 E)$, and mouse hippocampal neuronal cultures (Fig. $1 D$ ) by RT-PCR, cloning, and sequencing. Furthermore, we showed that pre- $(\alpha)$ pro-GDNF and pre- $(\beta)$ proGDNF mRNAs are expressed in embryonic E13, E15, E17, postnatal day 1 (P1), and P5 mouse kidney tissues but not in P6 mouse kidney, as reported previously for pre$(\alpha)$ pro-GDNF mRNA (Trupp et al., 1995; Suvanto et al., 1996) (Fig. $1 F$ ).

In cell lines and primary neurons, proteins encoded by pre- $(\boldsymbol{\alpha})$ pro-GDNF and pre- $(\boldsymbol{\beta})$ pro-GDNF cDNAs localize to Golgi compartment and secretory vesicles

Currently there are no antibodies available that are able to specifically detect endogenous human or murine GDNF in cell lines or in cultured primary neurons. Therefore, we had to rely on the analysis of transfected cells with exogenously expressed GDNF. The subcellular localization of GDNF encoded by pre- $(\alpha)$ pro-GDNF and pre-( $\beta$ )pro-GDNF was determined in NGF-differentiated neuronal-like PC-6.3 cells and in primary cortical neurons by IF analysis using anti-GDNF antibodies recognizing the mature part of GDNF and antibodies for subcellular marker proteins GM130 for cis-to medialGolgi (Nakamura et al., 1995) and MAP2 for neuronal dendrites. In addition, we raised an anti-pro-GDNF peptide antibody recognizing the pro-regions of $(\alpha)$ pro-GDNF and $(\beta)$ pro-GDNF (supplemental Fig. S1, available at www. jneurosci.org as supplemental material). The specificity of the anti-pro-GDNF antibody was shown by IF (supplemental Fig. S2, available at www.jneurosci.org as supplemental material) and WB analyses (supplemental Fig. S3, available at www.jneurosci. org as supplemental material).

In PC-6.3 cells, the GDNF-specific staining patterns detected and quantified were Golgi staining and vesicle-like staining, which could also include Golgi staining (Fig. 2A). GDNF encoded by pre- $(\alpha)$ pro-GDNF localized mainly to the Golgi area $(58 \pm 18.6 \%)$ and to some extent to vesicle-like structures (42 \pm $18.6 \%$ ) (Fig. $2 B$ ). In contrast, the majority of GDNF encoded by pre- $(\beta)$ pro-GDNF localized in vesicle-like structures (82 \pm $11.4 \%)$ and minority in the Golgi area $(18 \pm 11.4 \%, p=0.0023)$ (Fig. $2 B$ ). The localization of these proteins in PC-6.3 cells was further analyzed by immunoelectron microscopy (IEM). Both $(\alpha)$ pro-GDNF and $(\beta)$ pro-GDNF and their corresponding mature GDNFs were detected in some, but not all, of the dense core vesicles (DCVs) (Fig. 2C). Because the GDNF-specific staining is detected only in some DCVs, it is likely that this localization is not 
attributable to increased GDNF secretion caused by overexpression itself. Rather, the selective transport of the GDNF variant proteins by a subpopulation of DCVs takes place, suggesting that sorting of these proteins occurs in the Golgi complex. In addition, the GDNF-specific staining is seen in Golgi complex-associated transport vesicles (Fig. 2D).

In rat primary cortical and hippocampal neurons, similar vesicle-like immunostaining of GDNF, encoded by pre- $(\alpha)$ proGDNF and pre- $(\beta)$ pro-GDNF cDNAs, was seen along and at the tips of neurites (Fig. 3A) (supplemental Fig. S4, available at www.jneurosci.org as supplemental material). GDNF was localized to both MAP2-positive dendrites and MAP2negative axons (Fig. $3 A$ ). In the Golgi region, GDNF showed partial colocalization with GM130 (Fig. 3B). IF staining of primary cortical neurons with anti-GDNF and anti-pro-GDNF antibodies showed similar staining patterns, suggesting that noncleaved pro-GDNF or cleaved proregion together with mature GDNF is transported to the cell periphery in cortical neurons (Fig. 3C).

\section{$(\boldsymbol{\alpha})$ pro-GDNF and $(\boldsymbol{\beta})$ pro-GDNF are secreted in both mature GDNF and pro-GDNF forms from cell lines}

The GDNF variant proteins are synthesized in the forms of precursors, prepro-mature proteins (Fig. 1A,B). The pre-region, consisting of the signal sequence, is cleaved off during mRNA translation (Lin et al., 1993). The sizes of pro-regions of $(\alpha)$ pro-GDNF and $(\beta)$ proGDNF are 58 and 32 aa, respectively (Trupp et al., 1995) (Fig. 1A,B). The 134 aa mature GDNF proteins, produced by both splice variants, are most likely identical (Fig. $1 A, B$ ).

To study which forms of GDNF are secreted, pre- $(\alpha)$ pro GDNF and pre- $(\beta)$ pro-GDNF cDNAs were expressed in $\mathrm{CHO}$ cells and undifferentiated PC-6.3 cells. The cell lysates and media were analyzed by WB. In the cells and growth media, the antipro-GDNF antibody recognized two bands of $\sim 25$ and $20 \mathrm{kDa}$ or 22 and $18 \mathrm{kDa}$, respectively. Most likely these bands represent glycosylated and unglycosylated forms of $(\alpha)$ pro-GDNF and $(\beta)$ pro-GDNF (Fig. 4A,B). In addition, in the growth media, but not in cells, the anti-GDNF antibody recognized $15 \mathrm{kDa}$ band that corresponds to mature GDNF and 19 and $17 \mathrm{kDa}$ bands most likely representing intermediate cleavage products of $(\alpha)$ pro-GDNF and $(\beta)$ pro-GDNF (Fig. $4 A, B$ ). In PC-6.3 cells, in addition to antipro-GDNF-specific bands, the anti-GDNF antibody recognized several extra bands of $\sim 20 \mathrm{kDa}$ most likely representing intermediate cleavage products of $(\alpha)$ pro-GDNF and ( $\beta$ )pro-GDNF (Fig. $4 B$ ).

To confirm the secretion of $(\alpha)$ pro-GDNF and $(\beta)$ proGDNF, we used IF analysis and surface labeling as an additional method to detect extracellular pro-GDNF proteins. Differentiated PC-6.3 cells were cotransfected with GDNF binding receptor GFR $\alpha 1$ together with $(\alpha)$ pro-GDNF or $(\beta)$ pro-GDNF. IF stain- ings of stimulated cells with anti-GDNF, anti-pro-GDNF, and anti-GFR $\alpha 1$ antibodies showed that noncleaved $(\alpha)$ pro-GDNF and $(\beta)$ pro-GDNF or cleaved pro-regions together with mature GDNF are localized to the cell surface in the presence of GFR $\alpha 1$ (Fig. $5 A, B$ ). GFR $\alpha 1$ transfected or untransfected cells, incubated with exogenous recombinant mature GDNF protein, were used as positive and negative controls (data not shown).

\section{Proteolytic cleavage of pro-GDNF}

The pro-GDNF variant proteins contain a putative furin-like endoproteinase cleavage site $\operatorname{KRLKR}(-5$ to -1 ) (Lin et al., 1993) (Fig. 6A). To produce noncleavable pro-GDNF proteins, we mutated critical amino acids in the GDNF polypeptide. In $\operatorname{GDNF}(4 \mathrm{~A})$ mutant, lysines $(-5$ and -2$)$ and arginines $(-4$ and -1 ) were mutated to alanines, and, in $\operatorname{GDNF}(6 \mathrm{~A})$ mutant, lysines $(-5$ and -2$)$ and arginines $(-4,-1,11$, and 12$)$ were mutated to alanines (Fig. 6B). These proteins were expressed in $\mathrm{CHO}$ and NGF-differentiated PC-6.3 cells and detected in growth media by WB. The cleavage of the GDNF(4A) mutant was clearly reduced, and the cleavage of GDNF(6A) mutant was almost completely prevented (Fig. 6C,D). Compared with the WT GDNFs, the expression and secretion of $\operatorname{GDNF}(4 \mathrm{~A})$ and $\operatorname{GDNF}(6 \mathrm{~A})$ mutant proteins were increased (Fig. 6C,D). 
A

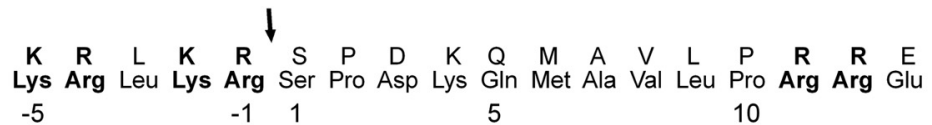

B

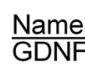

$-1 \quad 1$

10

\begin{tabular}{lll} 
& Mutation & Sequence \\
\hline GDNF(4A) & $\mathrm{R}(-4) /(-1) \mathrm{A}+\mathrm{K}(-5) /(-2) \mathrm{A}$ & $\rightarrow$ AALAASPDKQAAALPRRE
\end{tabular}

GDNF(6A) R(-4)/(-1)A $+\mathrm{K}(-5) /(-2) A+\mathrm{R} 11 / 12 \mathrm{~A} \longrightarrow$ AALAASPDKQAAALPAAE

C
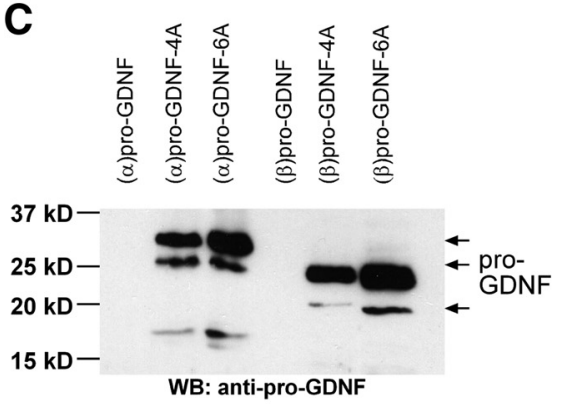

D
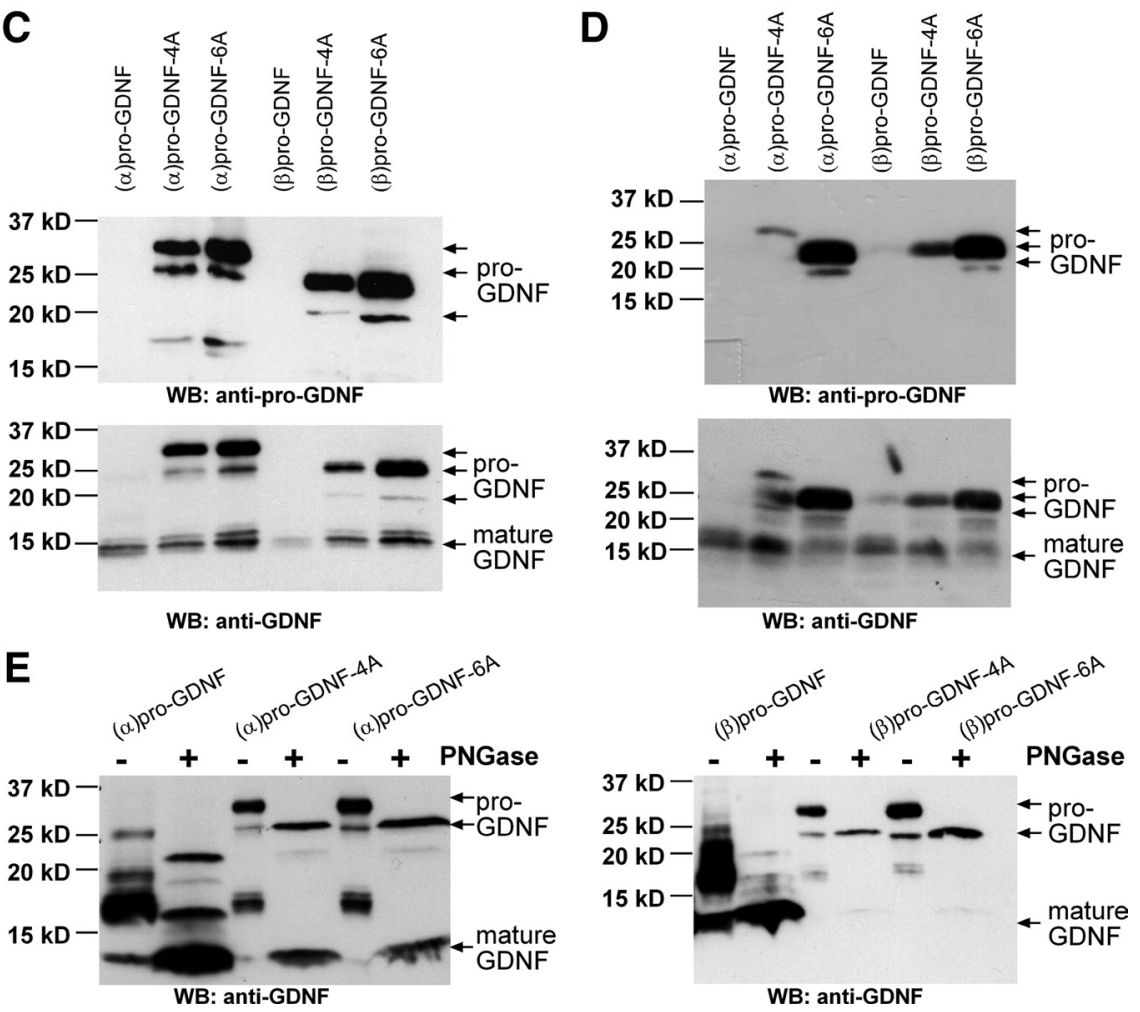

differentiated PC- 6.3 cells with or without furin endoproteinase inhibitor and broadspectrum MMP inhibitor (GM6001). PC-6.3 cells were also treated with $\alpha 2$ anti-plasmin. The results from the WB analysis of growth media show that furin inhibitor, MMP inhibitors, or $\alpha 2$ anti-plasmin do not prevent the cleavage of pro-GDNF to mature GDNF (Fig. 7A-C). However, furin inhibitor prevents the cleavage of the intermediate cleavage product of $\sim 20 \mathrm{kDa}$. In PC-6.3 cells, furin inhibitor also reduces the cleavage of pro-GDNFs (Fig. $7 B, C$ ). WT and uncleavable pro-NT3 were used as controls (Seidah et al., 1996b) (Fig. 7D). To determine whether other PCs are responsible for the cleavage of pro-GDNF into GDNF, we coexpressed PC1, PC2, PC5A, PC5B, PACE4, PC7, full-length furin, and soluble furin with human pro-GDNFs in constitutively secreting, furin-activity-deficient LoVo cells and analyzed the growth media by WB. The results demonstrate that furin, PACE4, PC5A, PC5B, and, to a lesser extent, PC7 effectively process $(\alpha)$ pro-GDNF to yield mature GDNF (Fig. 7E). Similar results were obtained for $(\beta)$ pro-GDNF (data not shown).

Figure 6. Specific amino acid substitutions in the GDNF pro-sequence and mature sequence reduce the cleavage of pro-GDNF. $A$, The amino acid sequence from -5 to 13 of the human $(\alpha)$ pro-GDNF and $(\beta)$ pro-GDNF sequences. The critical amino acids for pro-GDNF cleavage are bolded. An arrow indicates the putative cleavage site of pro-GDNF. B, GDNF(4A) and GDNF(6A) amino acid substitutions and resulting amino acid sequences from -5 to 13 of the human pro-GDNFS. $C, D$, Detection of GDNF from the media of transfected $C H O(C)$ and NGF-differentiated PC-6.3 (D) cells. Cells were transfected with human wild-type pre- $(\alpha)$ pro-GDNF or pre- $(\beta)$ pro-GDNF cDNA or the same CDNAs containing either GDNF(4A) or GDNF(6A) mutations. Cell media were collected and analyzed by Western blot using anti-pro-GDNF antibody and anti-GDNF antibody. $E$, Detection of GDNF from the media of transfected CHO cells. Cells were transfected with human wild-type pre- $(\alpha)$ pro-GDNF or pre- $(\beta)$ pro-GDNF cDNA or same cDNAs containing either GDNF(4A) or GDNF(6A) mutations. The media from wild-type pre- $(\alpha)$ pro-GDNF and pre- $(\beta)$ pro-GDNF transfected cells were concentrated. The samples were treated $(+)$ with PNGase $\mathrm{F}$, which removes N-linked glycans from proteins, or left untreated ( - ) and analyzed by Western blotting using anti-GDNF antibody. ( $-\boldsymbol{E}$, The bands representing $(\alpha)$ pro-GDNF, $(\beta)$ pro-GDNF, or mature GDNF are marked with arrows.

The mature GDNF polypeptide contains two putative $\mathrm{N}$-glycosylation sites (Lin et al., 1993). To determine whether the GDNF protein products detected in WB are glycosylated, we performed deglycosylation assay using PNGase F treatment. For this, we used the media of $\mathrm{CHO}$ cells expressing WT pro-GDNFs or proGDNFs containing either 4A or 6A mutations. Deglycosylation reduced the size of all WT pro-GDNF bands except the $\sim 10 \mathrm{kDa}$ band. This band most likely represents unglycosylated mature GDNF (Fig. $6 E$ ). After deglycosylation, pro-GDNFs carrying $4 \mathrm{~A}$ or $6 \mathrm{~A}$ mutations were detected as a single band corresponding to the lowermolecular-weight band of untreated controls, indicating that the upper band represents glycosylated form and the lower band unglycosylated form of pro-GDNFs (Fig. 6E).

This result is in an agreement with a recent publication showing that secreted GDNF is sensitive to N-glycosidase F (Oh-hashi et al., 2009).

To further characterize the cleavage of pro-GDNF into mature GDNF, we expressed WT pro-GDNFs in CHO and NGF-
For that, cells were stimulated with $50 \mathrm{~mm}$ $\mathrm{KCl}$ for $2 \mathrm{~h}$, and the response was measured in the presence or absence of a calcium chelator BAPTA-AM (with a 20 min pretreatment). The rat pre-pro-BDNF-EGFP (Haubensak et al., 1998), which secretion is known to be increased by $\mathrm{KCl}$, was used as a positive control (Chen et al., 2004). ELISA confirms that stimulation with $\mathrm{KCl}$ increases the secretion of $(\beta)$ pro-GDNF/ GDNF (178 $\pm 15 \%)$, as well as pro-BDNF-EGFP/BDNF-EGFP $(354 \pm 39 \%)$ to the growth medium (Fig. 8B). In addition, BAPTA-AM prevents this activity-dependent secretion of ( $\beta$ )pro-GDNF/GDNF $(126 \pm 27 \%)$ as well as pro-BDNF-EGFP/ BDNF-EGFP (169 $\pm 66 \%)$, indicating that $\mathrm{KCl}$ increases the secretion of these proteins in a calcium-dependent manner [for $(\beta)$ pro-GDNF, $p=0.0578$; for pro-BDNF, $p=0.0214$ ] (Fig. $8 B$ ). The secretion of $(\alpha)$ pro-GDNF/GDNF is slightly increased after $\mathrm{KCl}$ stimulation ( $139 \pm 28 \%$ ), but BAPTA-AM does not have any effect on its secretion $(134 \pm 29 \%)$, indicating that the increased secretion of $(\alpha)$ pro-GDNF/GDNF is not calcium dependent (Fig. 


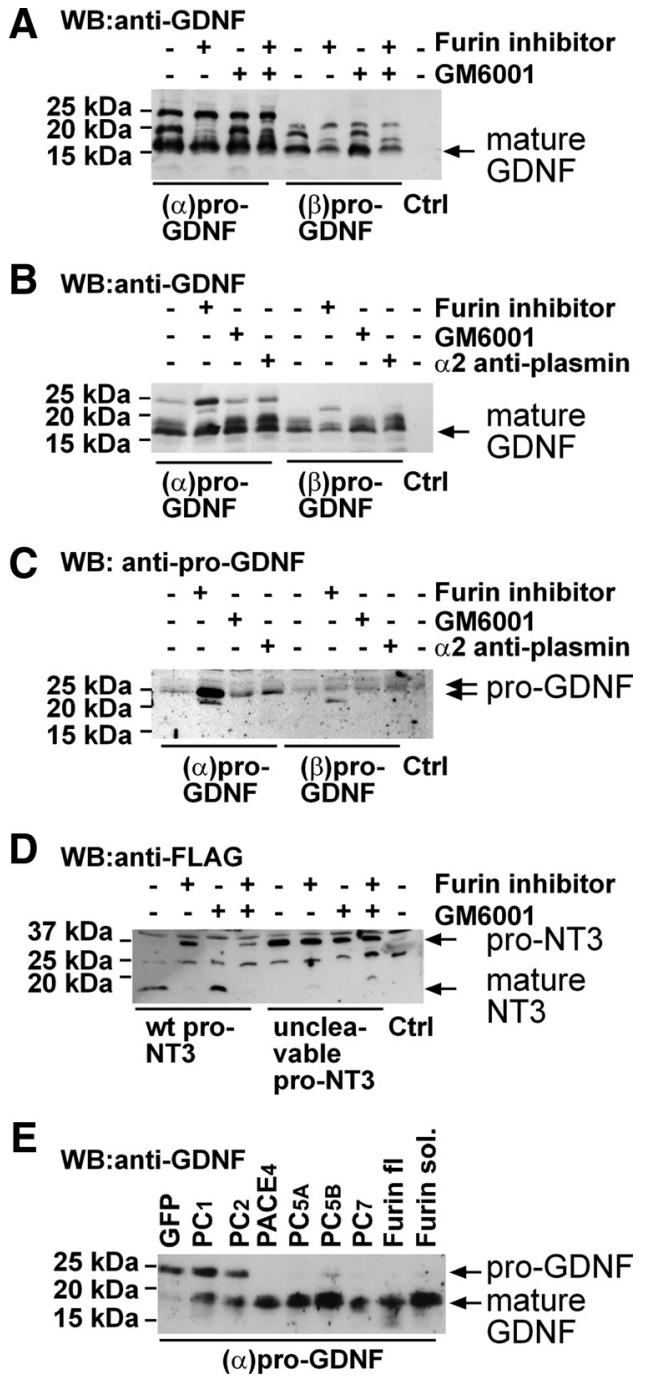

Figure 7. Furin, $P A C E 4, P C 5 A, P C 5 B$, and $P C 7$ can cleave pro-GDNF into mature GDNF. $A-D$, Furin inhibitor, MMP inhibitor GM6001, or $\alpha 2$ anti-plasmin was added to the media of transfected $\mathrm{CHO}$ ( $\boldsymbol{A}$, D) or NGF-differentiated PC-6.3 cells (B, C. After 48 h, media were collected, concentrated, and analyzed by Western blotting. Untreated media of transfected or nontransfected (Ctrl) cells were used as controls. $\boldsymbol{A}-\boldsymbol{C}$, Cells were transfected with pre- $(\alpha)$ pro-GDNF or pre- $(\beta)$ pro-GDNF cDNA and detected by WB using anti-GDNF antibody $(\boldsymbol{A}, \boldsymbol{B})$ or anti-pro-GDNF antibody ( $(\boldsymbol{C}$. The bands representing the final cleavage product of GDNF $(\boldsymbol{A}, \boldsymbol{B})$ or pro-GDNF $(\boldsymbol{C})$ are marked with arrows. $\boldsymbol{D}$, CHO cells were transfected with FLAG-tagged WT pro-NT3 or uncleavable mutant pro-NT3 encoding CDNA and detected from growth media by Western blotting using anti-FLAG antibody. The bands representing pro-NT3 and mature NT3 are marked with arrows. $E$, Pre- $(\alpha)$ pro-GDNF cDNA was coexpressed with PC family members in LoVo cells. Two furin constructs, full-length (fl) and soluble (sol.), were used. At $48 \mathrm{~h}$ after transfection, growth media were collected and analyzed by Western blot using anti-GDNF antibody. GDNF coexpressed with GFP was used as a control.

$8 B)$. These results demonstrate that, in neuronal-like PC-6.3 cells, the secretion of $(\beta)$ pro-GDNF/GDNF and not of $(\alpha)$ proGDNF/GDNF can be regulated in an activity-dependent manner. The subcellular staining patterns of exogenous pro-GDNF proteins were determined in NGF-differentiated PC-6.3 cells before and after $2 \mathrm{~h}$ stimulation with $50 \mathrm{~mm} \mathrm{KCl}$ by IF analysis using anti-GDNF and anti-GM130 antibodies. To stop the protein synthesis, $50 \mu \mathrm{g} / \mathrm{ml}$ cycloheximide was added to the cells simultaneously with $\mathrm{KCl}$. The GDNF-specific staining patterns detected were (1) Golgi staining and (2) vesicle-like staining (Fig. 2A). As shown by IF and IEM analyses, the vesicle-like staining most likely represents DCVs (Fig. $2 A, C$ ). The results show that, after $\mathrm{KCl}$ stimulation, the vesicle-like GDNF staining pattern is de- tected in the majority of cells expressing $(\beta)$ pro-GDNF (79 \pm $0.04 \%$ ) but in the minority of cells expressing $(\alpha)$ pro-GDNF $(21 \pm 0.03 \%)$, suggesting that, after stimulation, $(\beta)$ pro-GDNF/ GDNF move more rapidly to the DCVs than $(\alpha)$ pro-GDNF/ GDNF (Fig. 8C).

( $\beta$ )pro-GDNF and corresponding mature GDNF localize to secretogranin II and Rab3A-positive vesicles of regulated secretory pathway in differentiated neuronal-like PC-6.3 cells To characterize whether GDNF variant proteins localize to the vesicles of regulated secretory pathway, pro-GDNF proteins were expressed in NGF-differentiated PC-6.3 cells treated with or without $50 \mathrm{~mm} \mathrm{KCl}$ for $2 \mathrm{~h}$. GDNF was detected together with SgII, a marker protein for secretory granules of the regulated secretory pathway, by IF analysis and confocal microscopy, and the colocalization was quantified (Huttner et al., 1991; Dittie et al., 1995). The expression of rat pro-BDNF-EGFP protein, which is known to localize into the SgII-positive granules in neurons, was used as a positive control (Haubensak et al., 1998). The results show that the colocalization of $(\alpha)$ pro-GDNF/GDNF with $\mathrm{SgII}$ is very weak before and after $\mathrm{KCl}$ treatment (Pearson's coefficient: without $\mathrm{KCl}, 0.18 \pm 0.054$; with $\mathrm{KCl}, 0.16 \pm 0.069$ ) (Fig. $9 C)$. In addition, the areas of the strongest colocalization are located in the proximal region of cells (Fig. 9A). In contrast, the colocalization of $(\beta)$ pro-GDNF/GDNF with SgII before and after $\mathrm{KCl}$ treatment is strong (Pearson's coefficient: without $\mathrm{KCl}$, $0.53 \pm 0.037$; with $\mathrm{KCl}, 0.42 \pm 0.048$ ), and the areas of the strongest colocalization are located in the distal parts of the extensions (Fig. 9A,C). Thus, the colocalization of $(\beta)$ pro-GDNF/GDNF and SgII is significantly stronger than the colocalization of $(\alpha)$ pro-GDNF/GDNF and SgII (without $\mathrm{KCl}, p=0.000056$; with $\mathrm{KCl}, p=0.0073$ ), indicating that, in the cells, the majority of $(\beta)$ pro-GDNF/GDNF is localized in the SgII-positive granules of the regulated secretory pathway, whereas the majority of $(\alpha)$ pro-GDNF/GDNF is localized outside these structures (Fig. $9 C)$. Similarly to $(\beta)$ pro-GDNF/GDNF, the colocalization of pro-BDNF-EGFP/BDNF-EGFP with SgII before and after $\mathrm{KCl}$ treatment is strong (Pearson's coefficient: without $\mathrm{KCl}, 0.53 \pm$ 0.035 ; with $\mathrm{KCl}, 0.54 \pm 0.034$ ), and the areas of the strongest colocalization are found in the distal parts of the extensions (Fig. 9B, C).

$\mathrm{Rab}$ proteins are regulators of the secretory pathway (Zerial and McBride, 2001). To further characterize the localization of both $(\alpha)$ pro-GDNF and $(\beta)$ pro-GDNF, we coexpressed them with two different GFP-fused Rab proteins (Rab3A and Rab27A) known to regulate secretion and exocytosis in mammalian cells (Tsuboi and Fukuda, 2006). Our results show that both $(\alpha)$ pro-GDNF and $(\beta)$ pro-GDNF colocalize with Rab3A-WT on secretory vesicles (supplemental Fig. S5, available at www.jneurosci.org as supplemental material). The colocalization was seen with both anti-GDNF and anti-pro-GDNF antibodies (data not shown). In contrast, there was no colocalization of $(\beta)$ pro-GDNF with GFP or the dominantnegative mutant of Rab3A(T36N) (supplemental Fig. S5, available at www.jneurosci.org as supplemental material). Rab27A-WT colocalized also with both pro-forms of GDNF (data not shown).

\section{Discussion}

The function of the mature GDNF protein has been studied extensively. It was identified based on its ability to increase neurite length, cell size, and the number of dopaminergic neurons as well as its ability to stimulate high-affinity dopamine uptake in culture (Lin et al., 1993). GDNF is a potent factor for the protection and regeneration of nigral dopaminergic neurons against their toxininduced degeneration in animal models of PD and also in the 
A
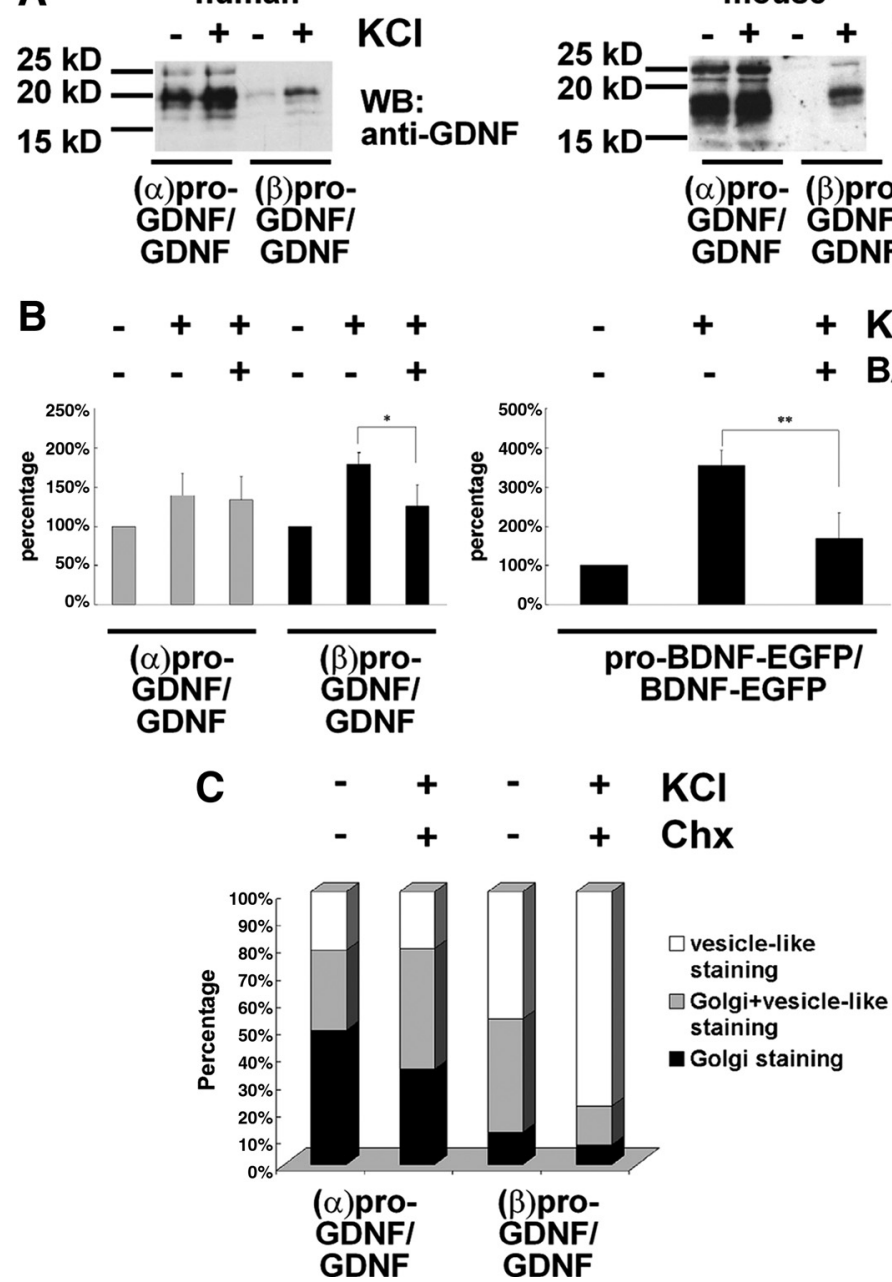

Figure 8. Neuronal depolarization-induced activity increases the secretion of ( $\beta$ )pro-GDNF and corresponding mature GDNF. $A, B$ Detection of GDNF and BDNF from the growth media of transfected NGF-differentiated PC- 6.3 cells. $A$, Western blotting analysis of the growth media from human or mouse pre- $(\alpha)$ pro-GDNF or pre- $(\beta)$ pro-GDNF cDNA transfected cells using anti-GDNF antibody. Cells were treated with $(+)$ or without $(-) 25 \mathrm{~mm} \mathrm{KCl} \mathrm{for} 5$ h. $\boldsymbol{B}$, ELISA of the growth media from human pre- $(\alpha)$ pro-GDNF, pre- $(\beta)$ pro-GDNF, and rat pre-pro-BDNFEGFP cDNA transfected cells. The cells were treated with (+) or without $(-) 50 \mathrm{~mm} \mathrm{KCl} \mathrm{and} 20 \mu \mathrm{mBAPTA}-\mathrm{AM}$ (with a 20 min pretreatment) for $2 \mathrm{~h}(n=3) .{ }^{*} p=0.0578 .{ }^{* *} p=0.0214$. Error bars show SD. C, Subcellular localization of proteins encoded by pre- $(\alpha)$ pro-GDNF and pre- $(\beta)$ pro-GDNF cDNA in NGF-differentiated PC-6.3 cells. The cells were either untreated $(-)$ or treated $(+)$ with $50 \mathrm{~mm} \mathrm{KCl} \mathrm{together} \mathrm{with} 50 \mu \mathrm{g} / \mathrm{ml}$ cycloheximide (Chx) for $2 \mathrm{~h}$. The quantification of the subcellular staining patterns is shown.

the protein encoded by pre- $(\beta)$ proGDNF localizes mostly in secretory vesicles and after stimulation moves more rapidly along the secretory pathway. Moreover, we show that the intracellular $(\beta)$ pro-GDNF and corresponding mature GDNF strongly colocalize with SgII, a marker protein for vesicles of the regulated secretory pathway, whereas intracellular $(\alpha)$ pro-GDNF and corresponding mature GDNF show less colocalization with SgII. In addition, $(\alpha)$ pro-GDNF and $(\beta)$ pro-GDNF colocalize with Rab3A and Rab27A, two known markers for secretory granules. Most importantly, we show by Western blot analysis and ELISA that $\mathrm{KCl}$ induced stimulation increases the secretion of $(\beta)$ pro-GDNF and corresponding mature GDNF, but not $(\alpha)$ pro-GDNF and corresponding mature GDNF, to the cell medium in a calcium-dependent manner. There is increasing evidence to suggest that there is more than a dual pathway of secretion (for review, see Saraste et al., 2009). Our results do not clearly show whether $(\alpha)$ pro-GDNF is secreted via constitutive pathway or an alternative pathway. Thus, more extensive studies are needed to clarify the early steps of GDNF secretion. One explanation for the difference between $(\alpha)$ pro-GDNF and $(\beta)$ pro-GDNF might be that $(\alpha)$ proGDNF is sorted less efficiently in forming secretory granules at the trans-Golgi network. This would explain why there is more of $(\alpha)$ pro-GDNF in the Golgi region. Because of inefficient sorting, some of $(\alpha)$ pro-GDNF might also be directed into the constitutive pathway. Our data suggest that the secretion mechanism of GDNF is different from that of BDNF, which is secreted as one isoform via either constitutive or regulated pathway. From neurons, BDNF is secreted mostly in an

treatment of patients with PD (Airaksinen and Saarma, 2002; Andressoo and Saarma, 2008). GDNF can also promote the development and survival of motoneurons, sensory neurons, enteric, parasympathetic, and sympathetic neurons. In addition, GDNF regulates kidney differentiation and spermatogenesis (Pichel et al., 1996; Meng et al., 2000; Airaksinen and Saarma, 2002). However, the cell biology of GDNF is poorly studied.

Here we have investigated the basic cell biology of the two splice isoforms of GDNF, including their intracellular localization, processing, cleavage, and secretion. The two GDNF splice variant mRNAs, pre- $(\alpha)$ pro-GDNF and pre- $(\beta)$ pro-GDNF, are widely expressed in the CNS and peripheral tissues. First, using immunofluorescence analysis of transfected NGF-differentiated PC-6.3 cells, we show that there is a clear difference in the subcellular localization and secretion of proteins encoded by pre$(\alpha)$ pro-GDNF and pre- $(\beta)$ pro-GDNF cDNAs in normal growth condition and after neuronal stimulation. Protein encoded by pre- $(\alpha)$ pro-GDNF localizes mostly in the Golgi complex and after stimulation moves gradually along the secretory pathway, whereas activity-dependent manner, after which it can have a variety of biological effects such as modulating synaptic transmission and synaptic plasticity (Mowla et al., 1999).

The functional importance of pro-neurotrophins has been revealed recently. Mature NGF and BDNF induce neuronal survival, differentiation, and synaptic modulation by binding to two tropomyosin-related receptor kinases A and B, respectively, and to the common receptor p75NTR (Huang and Reichardt, 2001). In contrast, uncleaved pro-BDNF and pro-NGF are proposed to induce cell death by binding to death receptor complex consisting of sortilin and p75NTR (Lee et al., 2001; Nykjaer et al., 2004; Teng et al., 2005). Our results from Western blot analysis show that overexpressed $(\alpha)$ pro-GDNF and $(\beta)$ pro-GDNF reside inside the cells mostly in the pro-form, and they can be detected in the growth media partially in the pro-form. Moreover, the results from IF analysis show that noncleaved $(\alpha)$ pro-GDNF and $(\beta)$ pro-GDNF or cleaved pro-regions together with mature GDNF are localized to the cell surface. We have done preliminary binding experiments of pro-regions of $(\alpha)$ pro-GDNF or $(\beta)$ pro- 


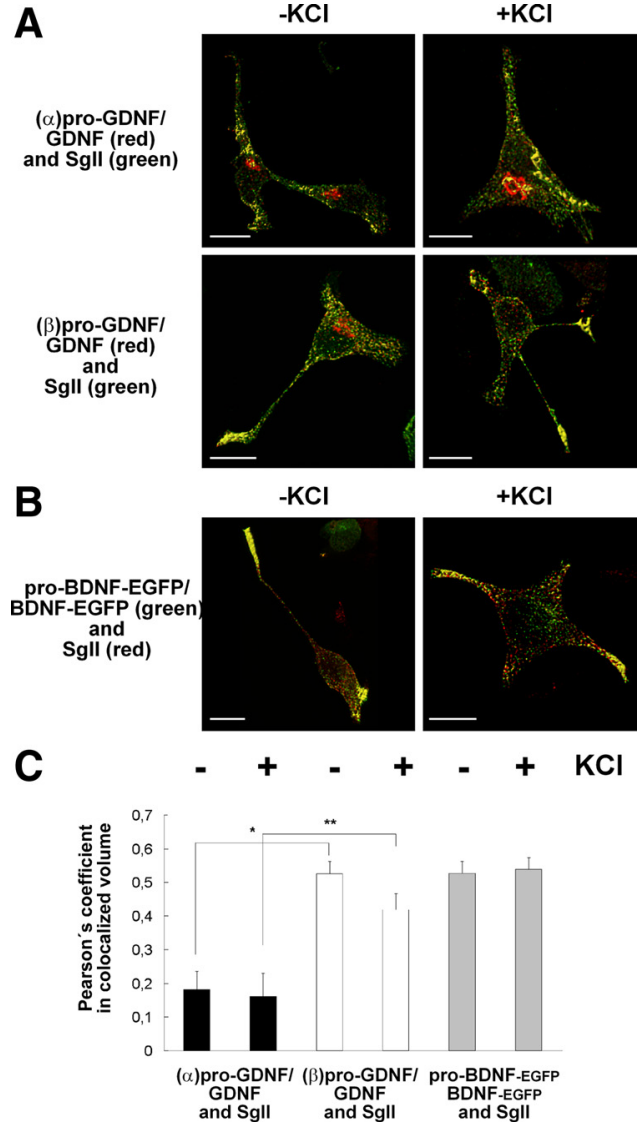

Figure 9. ( $\beta$ )pro-GDNF and corresponding mature GDNF colocalize with secretogranin II in NGFdifferentiated PC-6.3 cells. $A, B$, Confocal images of transfected NGF-differentiated PC- 6.3 cells. Cells were treated with $(+)$ or without $(-) 50 \mathrm{~mm} \mathrm{KCl}$ for $2 \mathrm{~h}$. Scale bars, $10 \mu \mathrm{m}$. $A$, Colocalization of overexpressed $(\alpha)$ pro- GDNF/GDNF (red) or ( $\beta$ )pro-GDNF/GDNF (red) and endogenous Sgll (green) immunoreactivities. The areas of strongest colocalization are highlighted with yellow isosurface. $\boldsymbol{B}$ Colocalization of overexpressed pro-BDNF-EGFP/BDNF-EGFP (green) with endogenous Sgll immunoreactivity (red). The areas of strongest colocalization are highlighted with yellow isosurface. $C$, Quantification of the level of colocalization shown as Pearson's coefficient in colocalized volume ( $n=$ $10-11) .{ }^{*} p=0.000056 ;{ }^{* *} p=0.0073$. Error bars show SEM.

GDNF with GFR $\alpha 1$ and could not detect binding, suggesting that pro-GDNF proteins, rather than pro-regions alone, bind to the cell surface (data not shown). This means that the proteolytic cleavage of pro-GDNF into mature GDNF may occur also outside the cells, most likely in the extracellular matrix. In addition, pro-GDNF proteins may remain uncleaved and have specific roles outside the cells. There are differences in the processing of $(\alpha)$ pro-GDNF and $(\beta)$ pro-GDNF when expressed from different expression plasmids. From the pAAV-MCS and pAAV-IREShrGFP expression vectors that have a stronger promoter and therefore result in higher protein expression, GDNF is detected inside the cells almost entirely in the pro-GDNF form (Fig. 4). Conversely, from pEGFP-N1 expression vector, which has a weaker promoter and therefore milder expression, GDNF is detected in both pro-GDNF and mature GDNF forms inside the cells (our unpublished data). To avoid misleading results attributable to very high overexpression, all experiments characterizing changes in the secretion of GDNF and BDNF induced by stimulation were done using pEGFP-N1 constructs. Based on sequence analysis, the pro-GDNF polypeptide has been proposed to have a putative furin-like endoproteinase cleavage site KRLKR $(-5$ to -1$)$ (Lin et al., 1993). However, it has never been carefully experimentally demonstrated that KRLKR site acts as a func- tional cleavage site and that furin endoproteinase is responsible for the cleavage of pro-GDNF to yield mature GDNF. We analyzed the processing of pro-GDNF by proprotein convertases, MMPs, and plasmin. We show that indeed furin, but also PACE4, PC5A, PC5B, and, to lesser extent, $\mathrm{PC} 7$ can process pro-GDNF in cell lines. In contrast, PC1 and PC2, MMPs, and plasmin do not cleave pro-GDNF. Pro-BDNF and pro-NFG have been shown to be processed into mature BDNF and NGF by furin, selective MMPs, plasmin, and less by PACE4 and PC5B (Seidah et al., 1996a,b; Lee et al., 2001). Thus, our results suggest that not only secretion of GDNF but also processing of GDNF is partially different from these of BDNF and NGF. To produce uncleavable pro-GDNF, we expressed pro-GDNF proteins with mutations in the KRLKR site and showed that these mutations are not sufficient to prevent the cleavage of pro-GDNF. Instead, additional mutations in the mature GDNF domain are needed.

Although the pre- $(\beta)$ pro-GDNF splice variant mRNA was characterized $>10$ years ago, the protein encoded by it has not really been studied. This is most likely because (1) the mature GDNF proteins, encoded by pre- $(\alpha)$ pro-GDNF and pre- $(\beta)$ proGDNF, are very likely identical and (2) the pro-GDNFs were considered predominantly inactive. However, one study characterizing some cell biological aspects of GDNF encoded by pre$(\beta)$ pro-GDNF has recently been published (Wang et al., 2008). This study demonstrates a dramatically decreased constitutive and regulated secretion for GDNF encoded by pre- $(\beta)$ proGDNF compared with GDNF encoded by pre- $(\alpha)$ pro-GDNF. The authors claim that this secretion deficit results from the accumulation of GDNF encoded by pre- $(\beta)$ pro-GDNF in the Golgi. In addition, they observed that both pre- $(\alpha)$ pro-GDNF and pre- $(\beta)$ pro-GDNF were secreted as mature GDNF forms. Our experiments give quite the opposite results. The main difference between these studies is that we have used the wild-type GDNF cDNAs without any tags, whereas Wang et al. have used cDNAs encoding C-terminally hemagglutinin (HA)-tagged GDNF. The C terminus of the mature GDNF protein is known to be critically important for its binding to GFR $\alpha 1$ receptor and RET activation, and it is highly possible that this modification also affects the trafficking and sorting of GDNF (Eketjäll et al., 1999; Parkash et al., 2008). Moreover, Wang et al. have used anti-HA antibodies to detect GDNF and pro-GDNFs, whereas we have produced an antibody recognizing the GDNF pro-region and were able for the first time to characterize specifically the pro-GDNFs.

Long-term in vivo expression of pre- $(\alpha)$ pro-GDNF by recombinant lentiviral vector delivery in the intact nigrostriatal dopamine system causes selective downregulation of tyrosine hydroxylase (TH) protein, a key enzyme in dopamine synthesis (Georgievska et al., 2004; Sajadi et al., 2005). Moreover, continuous in vivo expression of pre- $(\alpha)$ pro-GDNF by recombinant lentiviral vector delivery to the striatum of 6-hydroxydopamine lesioned Parkinsonian rats induces downregulation of TH in the preserved striatal dopamine terminals (Georgievska et al., 2002). This is most likely attributable to a compensatory mechanism, in which dopamine neurons under continuous GDNF stimulation are able to compensate for increased dopamine synthesis and release by decreasing TH enzyme activity. Recent experiments on nonhuman primates also indicate that high concentrations of GDNF can induce cerebellar toxicity (Lang et al., 2006). Therefore, future therapies should avoid high concentrations of GDNF and prefer systems in which the level of GDNF can be physiologically regulated. Our in vitro results showing that the secretion of GDNF encoded by pre- $(\beta)$ pro-GDNF can be regulated by biological stimuli make pre- $(\beta)$ pro-GDNF cDNA a more efficient 
therapeutic tool for gene therapy treatment of PD than pre$(\alpha)$ pro-GDNF cDNA that has been used until now.

\section{References}

Airaksinen MS, Saarma M (2002) The GDNF family: signalling, biological functions and therapeutic value. Nat Rev Neurosci 3:383-394.

Andressoo JO, Saarma M (2008) Signalling mechanisms underlying development and maintenance of dopamine neurons. Curr Opin Neurobiol 18:297-306.

Arai R, Geffard M, Calas A (1992) Intensification of labelings of the immunogold silver staining method by gold toning. Brain Res Bull 28:343-345.

Björklund A, Kirik D, Rosenblad C, Georgievska B, Lundberg C, Mandel RJ (2000) Towards a neuroprotective gene therapy for Parkinson's disease: use of adenovirus, $\mathrm{AAV}$ and lentivirus vectors for gene transfer of GDNF to the nigrostriatal system in the rat Parkinson model. Brain Res 886:82-98.

Chen ZY, Patel PD, Sant G, Meng CX, Teng KK, Hempstead BL, Lee FS (2004) Variant brain-derived neurotrophic factor (BDNF) (Met66) alters the intracellular trafficking and activity-dependent secretion of wild-type BDNF in neurosecretory cells and cortical neurons. J Neurosci 24:4401-4411.

Costes SV, Daelemans D, Cho EH, Dobbin Z, Pavlakis G, Lockett S (2004) Automatic and quantitative measurement of protein-protein colocalization in live cells. Biophys J 86:3993-4003.

Dittié AS, Tooze SA (1995) Characterization of the endopeptidase PC2 activity towards secretogranin II in stably transfected PC12 cells. Biochem J 310:777-787.

Durbec P, Marcos-Gutierrez CV, Kilkenny C, Grigoriou M, Wartiowaara K, Suvanto P, Smith D, Ponder B, Costantini F, Saarma M, Sariola H, Pachnis V (1996) GDNF signalling through the Ret receptor tyrosine kinase. Nature 381:789-793.

Eketjäll S, Fainzilber M, Murray-Rust J, Ibáñez CF (1999) Distinct structural elements in GDNF mediate binding to GFRalphal and activation of the GFRalpha1-c-Ret receptor complex. EMBO J 18:5901-5910.

Georgievska B, Kirik D, Björklund A (2002) Aberrant sprouting and downregulation of tyrosine hydroxylase in lesioned nigrostriatal dopamine neurons induced by long-lasting overexpression of glial cell line derived neurotrophic factor in the striatum by lentiviral gene transfer. Exp Neurol 177:461-474.

Georgievska B, Kirik D, Björklund A (2004) Overexpression of glial cell linederived neurotrophic factor using a lentiviral vector induces time- and dose-dependent downregulation of tyrosine hydroxylase in the intact nigrostriatal dopamine system. J Neurosci 24:6437-6445.

Grimm L, Holinski-Feder E, Teodoridis J, Scheffer B, Schindelhauer D, Meitinger T, Ueffing M (1998) Analysis of the human GDNF gene reveals an inducible promoter, three exons, a triplet repeat within the $3^{\prime}$-UTR and alternative splice products. Hum Mol Genet 7:1873-1886.

Haubensak W, Narz F, Heumann R, Lessmann V (1998) BDNF-GFP containing secretory granules are localized in the vicinity of synaptic junctions of cultured cortical neurons. J Cell Sci 111:1483-1493.

Huang EJ, Reichardt LF (2001) Neurotrophins: roles in neuronal development and function. Annu Rev Neurosci 24:677-736.

Huttner WB, Gerdes HH, Rosa P (1991) The granin (chromogranin/secretogranin) family. Trends Biochem Sci 16:27-30.

Keller P, Toomre D, Díaz E, White J, Simons K (2001) Multicolour imaging of post-Golgi sorting and trafficking in live cells. Nat Cell Biol 3:140-149.

Lang AE, Gill S, Patel NK, Lozano A, Nutt JG, Penn R, Brooks DJ, Hotton G, Moro E, Heywood P, Brodsky MA, Burchiel K, Kelly P, Dalvi A, Scott B, Stacy M, Turner D, Wooten VG, Elias WJ, Laws ER, et al. (2006) Randomized controlled trial of intraputamenal glial cell line-derived neurotrophic factor infusion in Parkinson disease. Ann Neurol 59:459-466.

Lang T, Wacker I, Steyer J, Kaether C, Wunderlich I, Soldati T, Gerdes HH, Almers W (1997) $\mathrm{Ca}^{2+}$-triggered peptide secretion in single cells imaged with green fluorescent protein and evanescent-wave microscopy. Neuron 18:857-863.

Lee R, Kermani P, Teng KK, Hempstead BL (2001) Regulation of cell survival by secreted proneurotrophins. Science 294:1945-1948.

Lin LF, Doherty DH, Lile JD, Bektesh S, Collins F (1993) GDNF: a glial cell line-derived neurotrophic factor for midbrain dopaminergic neurons. Science 260:1130-1132.

Matsushita N, Fujita Y, Tanaka M, Nagatsu T, Kiuchi K (1997) Cloning and structural organization of the gene encoding the mouse glial cell linederived neurotrophic factor, GDNF. Gene 203:149-157.

Meng X, Lindahl M, Hyvönen ME, Parvinen M, de Rooij DG, Hess MW,
Raatikainen-Ahokas A, Sainio K, Rauvala H, Lakso M, Pichel JG, Westphal H, Saarma M, Sariola H (2000) Regulation of cell fate decision of undifferentiated spermatogonia by GDNF. Science 287:1489-1493.

Mowla SJ, Pareek S, Farhadi HF, Petrecca K, Fawcett JP, Seidah NG, Morris SJ, Sossin WS, Murphy RA (1999) Differential sorting of nerve growth factor and brain-derived neurotrophic factor in hippocampal neurons. J Neurosci 19:2069-2080.

Nakamura N, Rabouille C, Watson R, Nilsson T, Hui N, Slusarewicz P, Kreis TE, Warren G (1995) Characterization of a cis-Golgi matrix protein, GM130. J Cell Biol 131:1715-1726.

Nykjaer A, Lee R, Teng KK, Jansen P, Madsen P, Nielsen MS, Jacobsen C, Kliemannel M, Schwarz E, Willnow TE, Hempstead BL, Petersen CM (2004) Sortilin is essential for proNGF-induced neuronal cell death. Nature 427:843-848.

Oh-hashi K, Ito M, Tanaka T, Hirata Y, Kiuchi K (2009) Biosynthesis, processing, and secretion of glial cell line-derived neurotrophic factor in astroglial cells. Mol Cell Biochem 323:1-7.

Parkash V, Leppänen VM, Virtanen H, Jurvansuu JM, Bespalov MM, Sidorova YA, Runeberg-Roos P, Saarma M, Goldman A (2008) The structure of the glial cell line-derived neurotrophic factor-coreceptor complex: insights into RET signaling and heparin binding. J Biol Chem 283:35164-35172.

Pichel JG, Shen L, Sheng HZ, Granholm AC, Drago J, Grinberg A, Lee EJ, Huang SP, Saarma M, Hoffer BJ, Sariola H, Westphal H (1996) Defects in enteric innervation and kidney development in mice lacking GDNF. Nature 382:73-76.

Pittman RN, Wang S, DiBenedetto AJ, Mills JC (1993) A system for characterizing cellular and molecular events in programmed neuronal cell death. J Neurosci 13:3669-3680.

Sajadi A, Bauer M, Thöny B, Aebischer P (2005) Long-term glial cell linederived neurotrophic factor overexpression in the intact nigrostriatal system in rats leads to a decrease of dopamine and increase of tetrahydrobiopterin production. J Neurochem 93:1482-1486.

Saraste J, Dale HA, Bazzocco S, Marie M (2009) Emerging new roles of the pre-Golgi intermediate compartment in biosynthetic-secretory trafficking. FEBS Lett 583:3804-3810.

Seemann J, Jokitalo EJ, Warren G (2000) The role of the tethering proteins p115 and GM130 in transport through the Golgi apparatus in vivo. Mol Biol Cell 11:635-645.

Seidah NG, Benjannet S, Pareek S, Chrétien M, Murphy RA (1996a) Cellular processing of the neurotrophin precursors of NT3 and BDNF by the mammalian proprotein convertases. FEBS Lett 379:247-250.

Seidah NG, Benjannet S, Pareek S, Savaria D, Hamelin J, Goulet B, Laliberte J, Lazure C, Chrétien M, Murphy RA (1996b) Cellular processing of the nerve growth factor precursor by the mammalian pro-protein convertases. Biochem J 314:951-960.

Suter-Crazzolara C, Unsicker K (1994) GDNF is expressed in two forms in many tissues outside the CNS. Neuroreport 5:2486-2488.

Suvanto, P, Hiltunen JO, Arumae U, Moshnyakov M, Sariola H, Sainio K, Saarma M (1996) Localization of glial cell line-derived neurotrophic factor (GDNF) mRNA in embryonic rat by in situ hybridization. Eur J Neurosci 8:816-822.

Teng, HK, Teng KK, Lee R, Wright S, Tevar S, Almeida RD, Kermani P, Torkin R, Chen ZY, Lee FS, Kraemer RT, Nykjaer A, Hempstead BL (2005) ProBDNF induces neuronal apoptosis via activation of a receptor complex of p75NTR and sortilin. J Neurosci 25:5455-5463.

Thomas K, Davies A (2005) Neurotrophins: a ticket to ride for BDNF. Curr Biol 15:R262-R264.

Tooze SA, Huttner WB (1990) Cell-free protein sorting to the regulated and constitutive secretory pathways. Cell 60:837-847.

Trupp M, Rydén M, Jörnvall H, Funakoshi H, Timmusk T, Arenas E, Ibáñez CF (1995) Peripheral expression and biological activities of GDNF, a new neurotrophic factor for avian and mammalian peripheral neurons. J Cell Biol 130:137-148.

Trupp M, Arenas E, Fainzilber M, Nilsson AS, Sieber BA, Grigoriou M, Kilkenny C, Salazar-Grueso E, Pachnis V, Arumäe U (1996) Functional receptor for GDNF encoded by the c-ret proto-oncogene. Nature 381:785-789.

Tsuboi T, Fukuda M (2006) Rab3A and Rab27A cooperatively regulate the docking step of dense-core vesicle exocytosis in PC12 cells. J Cell Sci 119: 2196-2203.

Wang Y, Geng Z, Zhao L, Huang SH, Sheng AL, Chen ZY (2008) GDNF isoform affects intracellular trafficking and secretion of GDNF in neuronal cells. Brain Res 1226:1-7.

Zerial M, McBride H (2001) Rab proteins as membrane organizers. Nat Rev Mol Cell Biol 2:107-117. 